\title{
LOS AYUNTAMIENTOS NO ESTAN OBLIGADOS AL PAGO DE LA CUOTA PATRONAL DE LA SEGURIDAD SOCIAL AGRARIA
}

\author{
$340.142: 368.4: 336.2 .027 .8$
}

por

\begin{abstract}
José Luis González-Berenguer Urrutia
\end{abstract}
SUMARIO: NORMATIVA A APLICAR.-II. LA JURISPRUDENCIA POSITIVA.-III. LOS PRINCIPIOS SOBRE LOS QUE DESCANSAN LA TOTALIDAD DE LAS SENTENCIAS.-IV. LA JURISPRUDENCIA NEGATIVA.-V. ANALISIS DE LA SENTENCIA DE 23 DE MARZO DE 1973.-VI. CONCLUSION.

\section{NORMATIVA A APLICAR}

Recientemente se han publicado en estas páginas dos trabajos sobre el presente tema, uno de los cuales llega a conclusiones harto pesimistas para los Ayuntamientos. Creo de interés dejar claro que sólo una, entre dieciocho sentencias del Tribunal Supremo, autoriza tal pesimismo. $\mathrm{Y}$ que hay trece sentencias posteriores a aquélla positivas para los Ayuntamientos. La doctrina del Tribunal es muy favorable para la tesis municipal, por consiguiente; tesis que además tiene apoyo en argumentos que hasta ahora nadie ha manejado y que constituyen, según creo, la aportación de este estudio.

Por otra parte, la Hacienda viene requiriendo a los Ayuntamientos propietarios de montes para el pago de la cuota a que alude el epígrafe. Creemos que tal pago no procede y ello por las razones que a continuación se exponen. 
La normativa a aplicar está constituida por la Ley de 23 de julio de 1971 (Boletín Oficial del Estado de 23 de septiembre) y Reglamento de 28 de diciembre de 1972 (Boletín Oficial del Estado de 19 de febrero de 1973). Para mayor comodidad transcribimos a continuación lo esencial de los textos citados:

Del texto refundido de la Ley:

Art. 44. 1. La cotización al Régimen Especial Agrario de la Seguridad Social será obligatoria para todos los empresarios comprendidos en el campo de aplicación de la presente Ley...

3. El importe global de la cotización empresarial se distribuirá entre los sujetos pasivos y exentos de la Contribución Territorial Rústica y Pecuaria, en función de jornadas teóricas, según clases y circunstancias de cultivos y aprovechamientos agrícolas forestales y ganaderos, en base a los datos de propiedad del Catastro de Rústica.

8. La cotización al Régimen de Accidentes de Trabajo y Enfermedades Profesionales se efectuará separadamente por cada empresario y de conformidad con la tarifa de primas oportunamente aprobada al efecto. Su régimen financiero será el que reglamentariamente se determine.

\section{Del texto del Reglamento:}

Art. 25. Cotización por accidentes de trabajo y enfermedades profesionales. La cotización de cada empresario al Régimen de Accidentes de Trabajo y Enfermedades Profesionales se efectuará de conformidad con las tarifas de primas que reglamentariamente se establezcan sobre las remuneraciones que efectivamente perciban los trabajadores por el trabajo que realicen por cuenta ajena, valoradas de acuerdo con las normas aplicables en el Régimen General.

Art. 27. Determinación de jornadas teóricas. 1. El importe global de la aportación equivalente a la cotización del sector empresarial por contingencias que no sean de accidentes de trabajo y enfermedades profesionales se distribuirá entre los sujetos pasivos de la Contribución Territorial...

Art. 28. 1. El pago de la aportación a que se refiere el artículo anterior, de acuerdo con lo dispuesto en el número $3 \mathrm{del}$ 
artículo 44 de la Ley del Régimen Especial Agrario de la Seguridad Social de 23 de julio de 1971, constituye, en todo caso, una obligación del propietario de las fincas indicadas en aquél...

Concluida esta exposición del Derecho positivo, queremos retener un dato clave: el que sólo el artículo 27 del Reglamento habla de los sujetos pasivos de la contribución, y ello exclusivamente para riesgos que no sean accidentes.

\section{LA JURISPRUDENCIA POSITIVA}

Primero. Nuestro más Alto Tribunal ha insistido rotundamente en la idea de que el simple propietario de terreno no está obligado al pago si no concurre en él, además, la condición de titular de empresa agrícola. Y así, la sentencia de la Sala $4 .^{a}$ de 23 de marzo de 1971 (Ponente Becerril), ha dicho:

Considerando: Que el tema propuesto a la declaración jurisdiccional es de si la condición de ser el Ayuntamiento recurrente sujeto pasivo de la Contribución Territorial Rústica y Pecuaria, en virtud de su titularidad dominical, arrastra la obligación de satisfacer la Cuota Empresarial del Régimen Agrario de la Seguridad Social no siendo empresario agrícola.

ConsIderando: Si todos los propietarios de fincas rústicas forestales o pecuarias, por el hecho del dominio, son titulares obligados al pago de la Cuota Empresarial del Régimen Especial Agrario de la Seguridad Social o de si, además, hace falta ser titular de una explotación agrícola...; es este concepto de titularidad de una explotación agraria el que ha de presidir la exégesis del precepto...; el problema de si la simple tenencia dominical de un predio rústico puede entenderse explotación agrícola...; si para ser sujeto pasivo basta sólo ser contribuyente por territorial o es necesario además ser empresario agrícola...; si faltan bienes o personas, falta el elemento personal y al propio tiempo la causa es preciso que se dé el binomio empresario-trabajador...; el recurrente no realizó por su cuenta empresa ni explotación agraria... ni empleó personal alguno dedicado a labores agrícolas, las cuotas no pueden serle aplicables...; ilógica consecuencia de que tendrán que pagar seguros quienes ni explotan, ni son empresas, ni tengan trabajadores asegurados.

Segundo. La sentencia de 15 de diciembre de 1972 dice:

CoNSIDERANDO: Viene determinada no por la condición de sujeto pasivo de la Contribución Territorial Rústica y Pecuaria, sino por la cualidad de empresario agrícola..., sin el cual no existe la relación patrón- 
trabajador, de manera que sin esta relación no puede darse la obligación de pago...; aparece acreditado...; no realizan por sí mismos los aprovechamientos de los montes de su propiedad, sino que son objeto de subasta...; carecen de la cualidad de empresarios y, consiguientemente, no vienen obligados a satisfacer Cuota Empresarial...; hay que recurrir a los conceptos generales del seguro...; darse, consecuentemente, la necesaria relación patrón-trabajador; tampoco existen riesgos que cubrir ni se produce, por ende, la obligación de pagar la prima...

Tercero: La sentencia de 16 de diciembre de 1972 (Ponente excelentísimo señor don Angel Martín del Burgo Marchán), ha dicho:

CONSIDERANDO: Al negar la condición de empresario... estimar la pretensión del mencionado Municipio..., siendo estos particulares los que tienen a su servicio a los asalariados necesarios, corriendo con las cargas de la Seguridad Social...

Cuarto: La sentencia, también de 16 de diciembre de 1972 (Aranzadi 5.136), ha dicho:

Considerando: El planteado en estas actuaciones por el tan citado Ayuntamiento, al negar la condición de empresario agropecuario, como presupone su inclusión en el padrón por el mismo impugnado; problema certeramente resuelto, como el anterior, por la Sala de Primera Instancia... en el sentido de estimar la pretensión del mencionado Municipio por haber probado el mismo que tal cuota se refiere a los montes cuyos aprovechamientos fueron adjudicados a unos particulares...

Quinto. La sentencia de 27 de diciembre de 1972 (Ar. 5.321) ha dicho:

Que no puede compartirse la tesis... que la Cuota Empresarial de la Seguridad Social está dirigida contra todos los registrados como sujetos pasivos de la Contribución Territorial Rústica y Pecuaria, ya que el artículo 46, 3, de la Ley de Régimen Especial Agrario de la Seguridad Social lo que esa norma establece es una simple presunción de que generalmente la titularidad de la empresa agraria coincide con el sujeto pasivo de la Contribución Rústica o Pecuaria, pero no que todo propietario de una finca rústica, forestal o pecuaria sea empresario agrícola...; resulta evidente que para la Ley de 31 de mayo de 1966 la condición de empresario no viene referida en función de la titularidad dominical de la finca, sino de la de ser titular de una explotación agraria; la Corporación recurrente paga Contribución Rústica, pero en los mismos no tiene personal agrícola de ninguna clase..., careciendo por ello de operarios propios en el monte en cualquier época del año, in- 
cluso en el momento de efectuarse los aprovechamientos, pues éstos se celebran mediante subasta pública y es el rematante -como empresario- quien procede a su corte, extracción, etc., empleando su propio personal, asegurado previamente...; en base de todo lo cual la no sujeción del Ayuntamiento referido al pago de la cuota debatida que la sentencia apelada proclama debe ser mantenida...

Sexto. La sentencia de la Sala 3. ${ }^{a}$ de fecha 5 de junio de 1973 ha dicho:

Considerando: La obligación de contribuir a la Seguridad Social Agraria no se deriva de la pura y simple titularidad dominical cuando no se realiza explotación agraria alguna por el titular dominical, sino que, por el contrario, se cede el aprovechamiento de la explotación al rematante de la subasta de un monte público, no cabe aplicar al titular dominical la sujeción a la referida cuota de la Seguridad Social... al no poderse considerar la referida cuota ni una exacción fiscal, ni un recargo de la Contribución Rústica y Pecuaria, a lo que se opondría el artículo 25 de la Ley de 11 de junio de 1964 de reforma de nuestro sistema tributario...; protección social del trabajador agrario queda asegurada a través de las cuotas que habrán de satisfacer los rematantes en las subastas...; el Ayuntamiento no emplea trabajador alguno en el aprovechamiento del expresado monte, ya que subasta su aprovechamiento...

Séptimo. La sentencia de la Sala 6. ${ }^{\mathrm{a}}$ de 16 de enero de 1974 ha dicho:

Considerando: Las indicadas dudas han sido ya resueltas en el sentido de que la Cuota Empresarial recae sobre los empresarios o titulares de las explotaciones agrícolas o forestales y no sobre los dueños de las fincas si éstos no explotan las mismas, si bien la sentencia de 23 de marzo de 1973 de dicha Sala 4. entendió lo contrario, lo hizo, como en ella se razona, teniendo en cuenta las peculiaridades del caso...

Octavo. La sentencia de 21 de enero de 1973, en materia social, siendo Ponente el excelentísimo señor don Luis Valle Abad, ha dicho:

Considerando: Que están obligados al pago los titulares de una explotación agrícola y no los dueños, uniforme línea jurisprudencial no alterada por la sentencia de 23 de marzo de 1973, que subraya la no identidad del caso por ella resuelto con los precedentes...

Noveno. La sentencia de 4 de abril de 1974, Sala 3.a, siendo Ponente el excelentísimo señor don Enrique Amat Casado, ha dicho: 
Considerando: Que la Cuota Empresarial sólo puede ser exigida a quienes ostenten la condición de empresarios, condición que no concurre en la Entidad local recurrente...

Décimo. La sentencia de 6 de abril de 1974, siendo Ponente el excelentísimo señor don Diego Espín Cánovas, ha dicho:

Considerando: La no sujeción a la Cuota Empresarial de quienes, pese a figurar como sujetos pasivos de la Contribución Territorial Rústica y Pecuaria, no sean titulares de empresa agraria, de donde se deduce que no basta para la sujeción a la Cuota Empresarial la mera titularidad dominical de las fincas, sino que es preciso la explotación de las mismas...

Undécimo. La sentencia de 8 de abril de 1974, siendo Ponente el excelentísimo señor don Enrique Amat Casado, dice:

Considerando: Que la Cuota Empresarial puede ser exigida a quienes ostenten la condición de empresarios, condición que no concurre en la Entidad local recurrente...

Duodécimo. La sentencia de la Sala 4." de 29 de octubre de 1974 (Ponente, excelentísimo señor don Enrique Medina Balmaseda), ha dicho:

La explotación de dicho monte está a cargo del Patrimonio Forestal del Estado..., es fácil observar y deducir que ni el Ayuntamiento recurrente tiene el carácter de empresario agrícola ni menos cuenta con personal de tal condición que le hagan sujeto pasivo de las cuotas giradas a su cargo, haciéndose obligada la estimación del recurso.

Decimotercero. Sentencia de 5 de noviembre de 1974 (Sala 4..2), Aranzadi 4.239 (Ponente, excelentísimo señor don Félix Hernández Tejedor). Dice:

Que el sistema económico financiero arbitrado por el vigente Régimen Especial Agrario de la Seguridad Social, configura como únicos factores contributivos a trabajadores, empresarios, Seguridad Social General y el Estado. Así lo proclama la Exposición de Motivos, punto 9 de la Ley de 31 de mayo de 1966 y lo desarrolla su articulado, de modo particular los artículos 43 y 44 en relación con la cotización de los trabajadores, y el 46 en sus diversos apartados que regula la cotización empresarial. La normativa vigente, pues, se abstiene de imponer la obligación de cotizar a otras personas abstracción hecha del Estado y la Seguridad Social General, que no sean las que participen 
con el carácter de trabajadores o empresarios en el proceso de la producción agraria.

Que no contradice ni deroga el enunciado principio legal básico, del sistema, la previsión que el número 4 del artículo 46 contiene cuando dispone que la cotización empresarial se recaudará conjuntamente con la Contribución Territorial, pues en el examen comparativo de los citados preceptos queda perfectamente claro que el ordenamiento legal distingue y trata separadamente los conceptos de cotización empresarial y el procedimiento para su recaudación, estableciendo, por lo que a la función recaudatoria se refiere, el sistema de hacerla efectiva paralela o conjuntamente con la Contribución Territorial, pero sin que ello prejuzgue que el sujeto pasivo de este tributo sea también la persona sobre la cual recae la obligación de cotizar, a menos que al mismo tiempo ostente el carácter de empresario. En los demás casos el titular de la Contribución Territorial es designado por la Ley, por razones de simplificación del procedimiento recaudatorio, únicamente como intermediario del pago que le anticipa, pero que en definitiva repercutirá en los verdaderos empresarios agrícolas que exploten las fincas en arrendamiento, aparcería o título análogo de disfrute. En todos estos supuestos la obligación de cotizar se basa exclusivamente en la existencia de una empresa agraria, mientras que la atribución del pago en el procedimiento recaudatorio se basa, en principio, en la presunción de que el contribuyente sea también el empresario, estableciéndose a continuación una forma de subrogación legal cuando no se dé tal coincidencia, a fin de que en definitiva el pago venga a recaer sobre el titular de la empresa, única entidad a que nuestro sistema legal atribuye el carácter de factor contributivo de las cuotas en conjunción con el trabajador, el Estado y la Seguridad Social General.

Que lógicamente se infiere de cuanto queda dicho: a) que la existencia de una empresa agrícola es supuesto indispensable para que haya lugar a cotización por ella en el Régimen Especial Agrario; b) que la titularidad de la Contribución Territorial no determina por sí misma la obligación de cotizar, pues la recaudación a través de ella constituye un medio accesorio de efectuar o anticipar el pago, pero sólo cuando éste sea debido, por mediar la existencia de una empresa agrícola.

Decimocuarto. Sentencia de 14 de noviembre de 1974. ContAdministrativo (Sala 3. ${ }^{\mathrm{a}}$ ), Ar. 4.360 (Ponente, excelentísimo señor don Nicolás Gómez de Enterría y Gutiérrez). Dice:

ConsIDERANDo: Que de acuerdo con el criterio establecido en numerosísimas sentencias de esta Sala, siguiendo el asimismo proclamado por el Tribunal Supremo en sentencia de 9 de junio de 1970 y, sobre todo, en la de 23 de marzo de 1971, la Cuota Empresarial del Régimen de la Seguridad Social Agraria, y por tratarse de un seguro obligatorio, por razones y finalidades de orden social en el que es preciso que se dé el binomio empresario-trabajador, sólo pueda ser exigida a quienes 
ostenten la condición de empresarios, condición que no concurre en la Entidad local recurrente, ya que, según certificaciones aportadas en período probatorio, aquella Corporación no tiene personal afecto a la explotación de los montes de su propiedad inscritos en el catálogo de utilidad pública, por lo que no tiene constituida empresa agraria, puesto que el personal que allí trabaja lo hace por cuenta de ICONA o de los adjudicatarios de los aprovechamientos de maderas, y ante la realidad de estos hechos debe estimarse el recurso.

Decimoquinto. Sentencia de 20 de noviembre de 1974 (Sala 3.a), Aranzadi 4.516 (Ponente, excelentísimo señor don Diego Espín Cánovas). Dice:

Que de acuerdo con el criterio establecido en numerosísimas sentencias de esta Sala. siguiendo el asimismo proclamado por el Tribunal Supremo en sentencia de 9 de junio de 1970, y sobre todo en la de 23 de marzo de 1971, la Cuota Empresarial del Régimen de la Seguridad Social Agraria, y por tratarse de un seguro obligatorio, por razones y finalidades de orden social, en el que es preciso que se dé el binomio empresario-trabajador, sólo puede ser exigida a quienes ostenten la condición de empresarios, condición que no concurre en la Entidad local recurrente, puesto que el personal que allí trabaja lo hace por cuenta de ICONA o de los adjudicatarios de los aprovechamientos de maderas, y ante la realidad de estos hechos, debe estimarse el recurso.

De donde se deduce que no basta para la sujeción a la Cuota Empresarial la mera titularidad dominical de las fincas sujetas a la Contribución Rústica y Pecuaria, sino que es preciso la explotación de las mismas en concepto de empresario o titular de una explotación agraria, basándose también en los principios que informan nuestro Derecho tributario, por lo que no es preciso reiterar in extenso lo allí expuesto.

Decimosexto. La sentencia de 19 de febrero de 1975 dice:

Considerando: Que la problemática jurídica que plantea el presente proceso viene limitada a determinar la legalidad, por razones de derecho material, de la resolución del Ministerio de Trabajo de 28 de junio de 1968, en cuanto denegatoria del recurso de alzada interpuesto por la representación del Ayuntamiento de Sinarcas (Valencia) contra decisión de la Dirección General de Previsión de 20 de marzo anterior, que a su vez desestima la pedida exención de la cotización empresarial al Régimen Especial Agrario de la Seguridad Social, pues si bien el Ayuntamiento actor es titular dominical de los montes de propios números 56 y 57 del catálogo de los de utilidad pública de la Provincia de Valencia, no tiene el carácter o conceptuación de empresario agrícola ni dispone de personal a su servicio en los montes que se encuentran bajo la tutela del distrito forestal y sometidos, en lo que se refiere a su explotación, conservación, etc., a las disposiciones de la vigente Ley de Montes. 
ConsIDERANDo: Que del examen del expediente administrativo se desprende que la Corporación recurrente es propietaria de dos montes públicos catalogados por los que satisfacer Contribución Rústica, pero sin que en los mismos disponga de personal agrícola de ninguna clase al venir sometidos al régimen jurídico previsto en la legislación especial del ramo sobre conservación, vigilancia, mejora y explotación de los montes, etc., y por ello el Ayuntamiento demandante no puede ser conceptuado de empresario agrícola ni tampoco de titular de una explotación agraria (en los términos que en extenso se razona en las sentencias de 23 de marzo de 1971 y 27 de diciembre de 1972, etc.) ni resultar posible legalmente la repercusión, en todo caso, de las cuotas de la Seguridad Social Agraria a los adjudicatarios o rematantes de los aprovechamientos forestales sometidos ya al Régimen General de la Seguridad Social que la disposición final 9.a de la Ley de 31 de mayo de 1966 mantiene o reitera y que el artículo 5..$^{\circ}$ del Reglamento de 23 de febrero de 1967 reproduce por resultar tan sólo el actor propietario de fincas catalogadas de montes de utilidad pública, sometidos en lo referente a explotación, etc., al Régimen de la Ley de Montes, y es sabido que incluso en el momento de efectuarse los aprovechamientos éstos se celebran mediante la técnica de la subasta pública y es el rematante -como empresario - quien procede a la realización de las operaciones

- materiales precisas, empleando su propio personal, previamente asegurado por imperativo legal, lo cual impone el rechazo de la tesis de la Administración, pues en otro caso nos encontrariamos con un supuesto de doble cotización, aparte de un desbordamiento jurídicamente inaceptable del concepto de empresario agrícola y de lo que debe entenderse por aSeguridad Social Agraria», como seguro obligatorio, en los correctos términos expuestos por la sentencia de la Sala de 23 de marzo de 1971.

Decimoséptimo. Y, finalmente, en la sentencia de 9 de mayo de 1975 (Sala 4.", Ponente don Aurelio Botella Taza) el Tribunal Supremo dice:

CONSIDERANDO: Que en el presente recurso contencioso-administrativo se plantea la cuestión de si un Ayuntamiento, el de Puebla de San Miguel, en la Provincia de Valencia, por el simple hecho de ser titular do minical de finca rústica y sujeto pasivo de la correspondiente Contribución Territorial, estaba también obligado a satisfacer las cuotas empresariales de la Seguridad Social Agraria.

En cuanto a la cuestión enunciada al principio, que fue ya la misma decidida en sentencia de esta Sala de 23 de marzo de 1971, reiterándose su doctrina, entre otras, en las de 23 de octubre de 1974 y 21 de marzo de 1975, según las cuales, y en concordancia con numerosas de la Sala Tercera, entre ellas las de 16 y 27 de diciembre de 1972, precisa distinguir entre titularidad del inmueble y la de la empresa o explotación agrícola forestal o pecuaria para asignar exclusivamente a la segunda 
la obligación de cotizar la Cuota Empresarial, sin que a esta hermenéutica sean óbice cuantos argumentos se aducen en el escrito de contestación a la demanda principalmente basados en las peculiares modalidades recaudatorias y de cálculo global pertinentes a la Cuota de referencia, pues aun siendo cierto, como indudablemente lo es a tenor del artículo 46 , número $3 .^{\circ}$, de aquella Ley y del 24 , números $2 .^{\circ}$ y $3 .^{\circ}$, de su Reglamento, que el importe conjunto de la cotización empresarial se hará efectivo inicialmente distribuyéndolo entre todos los sujetos pasivos de la Contribución Territorial Rústica y Pecuaria en proporción a la base imponible de la misma que a cada uno corresponda, tal disposición no es independiente de lo establecido en el número primero del artículo 46 referenciado, donde se define la cotización de que se trata como sólo obligatoria para los empresarios, sean o no trabajadores por cuenta propia, y esta condición de empresario es a su vez definida en el artículo $4 .^{\circ}$ de la Ley y 7. explotación agraria, concepto económico y meta jurídica, pero que, de modo coherente con la naturaleza de la cosa por él representada, cumple referir a la unidad productiva con autonomía de decisiones en actividad correspondiente al sector primario de la economía y con integración, por tanto, de los factores de la producción, entre ellos el trabajo, por lo cual el citado artículo 4..$^{\circ}$ de la Ley de 1966 establece en su último inciso que en cualquier caso se reputará empresario a quien ocupe trabajadores por cuenta ajena en labores agrarias, de donde se infiere que si bien la distribución de la cuota global ha de hacerse entre los propietarios de fincas rústicas sujetos pasivos de la contribución, será ello solamente entre todos los cualificados por la condición de empresario agrícola.

El recurrente acredita, en virtud de las certificaciones unidas al expediente administrativo, que no tiene ningún trabajador en los montes de propios del catálogo de los de utilidad pública por cuya titularidad dominical fuese contribuyente de rústica, y que cuando son aprovechados, de acuerdo con normas específicas del Distrito Forestal, la explotación es cedida mediante contrato administrativo y trámite de subasta, actuando siempre el adjudicatario como empresa a su propio nombre por cuya cuenta contrata a los trabajadores y satisface con independencia las cuotas de la Seguridad Social, hechos a los que además ninguna oposición concreta se aduce al contestar la demanda, y su consecuente estimación como probados subsume el caso en las hipótesis a que es aplicable la doctrina de anterior exposición, infiriéndose de ello la necesidad de entender excluido al Ayuntamiento accionante de toda obligación de cotizar al Régimen Especial Agrario de la Seguridad Social en razón a los montes de que es simple propietario. 


\section{LOS PRINCIPIOS SOBRE LOS QUE DESCANSAN LA TOTALIDAD DE LAS SENTENCIAS}

De la exposición del precedente conjunto de normas y de sentencias producidas en aplicación de las mismas se pueden deducir los siguientes principios, cuya existencia es evidente por lo demás.

Primero. Principio de la injusticia del doble pago.

Aparece recogido fundamentalmente en el artículo $2 .^{\circ}$ de la Ley vigente. Según él se exceptúan del Régimen de la Seguridad Social Agraria «los trabajadores comprendidos en el Régimen General». También aparece recogido en el artículo 69 del Reglamento, que evita el doble aseguramiento.

El principio, por otra parte, informa la totalidad de la jurisprudencia vista.

Segundo. Principio de la no identificación entre las figuras de propietario y empresario del monte, correspondiendo sólo a este último el pago de la cuota empresarial.

Tal principio se deduce de los artículos $4 .^{\circ}$ de la Ley y $2 .^{\circ}$ y $7 .^{\circ}$ y 69 del Reglamento, sin que pueda interpretarse como contrario a ellos lo dispuesto en el artículo 44 de la Ley (que, por otra parte, es reproducción exacta del artículo 46, apartado 3 , del anterior texto de 1966, sobre el que se produjeron las sentencias citadas).

En efecto, el artículo $4 .^{\circ}$ define al empresario (obligado al pago de la cuota patronal) como "el titular de una explotación", sin aludir para nada al propietario.

El apartado 2 del artículo $7 .^{\circ}$ del Reglamento aclara que «el titular de una explotación podrá serlo por su condición de propietario, arrendatario $\mathrm{u}$ otro concepto análogo». $\mathrm{Y}$ a este empresario (que puede no ser el propietario) es al que corresponde la cotización.

Pues bien, aquí aparece una distinción, distinción importantísima, contenida en el capítulo IV del propio Reglamento, cuya sección $1 .^{a}$ se dedica a la "cotización por las empresas", y dice (en el artículo 25) que aquéllas (los empresarios y no los propietarios) pagarán «de conformidad con las tarifas de primas que reglamentariamente se establezcan sobre las remuneraciones que efectivamente perciban los trabajadores». Y ello en cuanto "al Régimen de Accidentes de Trabajo y Enfermedades Profesionales». En cuan- 
to a los restantes riesgos (los que no sean accidentes y enfermedades), el importe global de la "cotización empresarial se distribuirá entre los sujetos pasivos de la contribución territorial rústica», aunque estén, según reza el artículo 27 , exentos. Y el artículo siguiente (el célebre artículo 28) dice que «el pago de la aportación a que se refiere el artículo anterior (es decir, la aportación que no sea para los riesgos de accidentes y enfermedades)... constituye una obligación del propietario de las fincas, utilice o no mano de obra ajena, y sin perjuicio del derecho que le asiste a repercutir...».

Hay otro argumento. $Y$ es el de que el artículo 44 de la Ley actual reproduce exactamente el artículo 46, apartado 3, de la Ley de 1966 (de la que la actual es refundición). Y a la vista del mismo los Tribunales, una y otra vez, interpretaron que las figuras del empresario (siempre obligado al pago) y propietario (sólo obligado al pago si es empresario) no eran identificables. Nos remitimos a las enérgicas declaraciones jurisprudenciales transcritas.

Finalmente, y como tercer argumento, digamos ser cierto que los propietarios, por el hecho de serlo, están obligados al pago de una parte (por cierto, forzosamente pequeñísima) de la cuota empresarial: aquella que cubre los riesgos que no sean accidentes ni enfermedades profesionales. La parte de prima que cubre estos dos importantísimo riesgos (es decir, la casi totalidad de la prima), no tiene en ningún caso absolutamente nada que ver con los «sujetos pasivos de la contribución territorial", esto es, con los propietarios. Así se deduce claramente de los artículos 25,27 y 28 del Reglamento, número 8 del artículo 44 de la Ley. Sólo cuando la Seguridad Social calcule los importes de ambas porciones de las primas (la que cubre los riesgos importantes y la que cubre los otros riesgos) podrá reclamar a los dueños el pago.

Tercero. Principio de la cobertura del riesgo.

Ahora vemos técnicamente desarrollado en las normas el principio de justicia elemental, que nos dice que no pueden pagarse primas doblemente para cubrir un mismo y único riesgo. Esta instrumentación aparece ahora en los artículos 34 y 40 de la Ley y 20, 21, 22 y 25 del Reglamento. Todos ellos aluden a la formación de una "adecuada y suficiente cobertura»; a la "proporción entre los recursos y el número de trabajadores censados...»; «los empresarios, para cubrir las contingencias de accidentes de trabajo y enfermedad profesional de los trabajadores que estén a su servi- 
cio, deberán llevar un libro de matrícula del personal, en el que serán inscritos todos los trabajadores que empleenn.

Este principio de cobertura del riesgo parece reiteradamente reconocido por las sentencias que se han citado. La Ley conecta directamente los conceptos de riesgo y prima. Se paga en proporción a los trabajadores «que se empleen». Otra cosa sería absurda, injusta e ilógica.

Cuarto. Principio de la repercutibilidad.

En conexión con lo anterior, la Ley permite que los propietarios, si no son empresarios, paguen la cuota. Pero sólo en el caso de que ésta sea repercutible en un tercero que deba pagarla (por no haber pagado él). Y a ello aluden los artículos 44, apartado 7, de la Ley y 27 y 28 del Reglamento. Pero obsérvese que en los casos presentes no hay tal posibilidad de repercusión. Y ello por la sencilla razón de que los adjudicatarios de las subastas no la admitirían, ya que alegarían que el riesgo que se asegura mediante las primas que se les intenta repercutir ya está cubierto. Y si las Corporaciones pusieran tal cláusula en las convocatorias de sus subastas, y, no obstante ello, los contratistas acudieran, sería a base de rebajar de su oferta el precio de estas primas. Quiere decirse que en el presente caso la repercusión es matemáticamente imposible.

\section{LA JURISPRUDENCIA NEGATIVA}

Aunque en rigor no puede hablarse de jurisprudencia, puesto que se trata de una sola sentencia, frente a la unánime tesis anterior, la Sala 4. ${ }^{\text {, }}$, en sentencia de 23 de marzo de 1973, ha dicho:

ConsIDERANDo: Que el problema que se suscita pudo concretarse en que, si bien conforme a la tesis sustentada por la Administración, resulta que, de acuerdo con el artículo 46, números 1 y 30 , de la Ley de la Seguridad Social Agraria de 31 le mayo de 1966 y en el artículo 24 de su Reglamento de 23 de febrero de 1967 -disposiciones que son las aplicables a este caso-, los obligados al pago de la Cuota Empresarial en el Régimen Especial Agrario son todos los sujetos pasivos en la Contribución Territorial Rústica y Pecuaria, es decir, todos los titulares de explotaciones agrarias; en cambio, dicha litigante aduce en apoyo de su tesis que la Cuota Empresarial aludida es obligatoria no para todos los sujetos pasivos de la Contribución Rústica y Pecuaria, sino sólo, según señala el párrafo $10^{\circ}$ del artículo 46 de la Ley, para el empresario comprendido en el campo de aplicación del expresado Régi- 
men Especial Agrario y el que viene definido en el artículo $4 .^{\circ}$ de la misma, como todo titular de una explotación agraria.

ConsIDERANDo: Que una vez planteada en estos términos la cuestión litigiosa, la solución más acertada es la que se ha dado por las resoluciones administrativas que se impugnan en este recurso contenciosoadministrativo, porque, además de la argumentación que en ellas se contiene para fundamentarlo, viene a corroborarse y confirmarse en razón de lo siguiente: $1 .^{\circ}$ Que la explotación de los montes, en definitiva recae en beneficio del Ayuntamiento propietario; 2. $\mathrm{El}$ carácter especial que reviste el Régimen Agrario de la Seguridad Social por la específica naturaleza de la economía y explotación agrícola, lo que hace que se asiente sobre bases que necesariamente tienen que disentir del Régimen General de la Seguridad Social; 3.० Además, la Ley no fija las cotizaciones empresariales individualizadas en función de la mano de obra empleada concretamente para cada empresa, que resulta imposible controlar; 4. $\mathrm{El}$ carácter provisional de implantarse este seguro especial en la forma con que inicialmente se regula y que no impide el poder reemplazarlo en su día por cualquier otro procedimiento de mejor determinación objetiva; $5^{\circ}$ La circunstancia, como antes se dice, de poder repercutir conforme al número 5 del artículo 46 de la Ley de 31 de mayo de 1966 y artículo 26 de su Reglamento de 23 de febrero de 1967, los propietarios de las fincas rústicas el importe de las cuotas correspondientes a su cotización, que pagaron por este concepto y que tienen cedidas en arrendamiento, aparcería o sistema análogo - como el de adjudicación mediante subasta, que se viene efectuando por dicho Ayuntamiento- a los explotadores; 8. Que el espíritu y la letra de la legislación rectora de estos Seguros Sociales no puede asemejarse en todos sus rasgos a la que regula la de los demás Seguros Sociales en general, y en vista de ello es claro que si, en definitiva, también aquí juega el binomio empresario-trabajador, clásico en esta clase de seguros, no lo es ni puede serlo de igual forma que en los demás, dadas sus especiales y singularísimas peculiaridades, que ponen de manifiesto el que si bien se establece la obligación de cotizar a los empresarios, en principio se les atribuye esta condición al conceptuárseles como simples sujetos pasivos de ellos a los propietarios de fincas rústicas agrícolas o forestales, sin perjuicio de los subsiguientes derechos de su repercusión a quienes se les haya transferido el poder explotarlas directamente.

Considerando: Que en nada afecta a lo antes expuesto el que el Ayuntamiento recurrente carezca de obreros o trabajadores al servicio de sus montes, ni la forma de explotarlos, ni el porcentaje que tenga que entregar al Patrimonio Forestal del importe de sus productos, sino que basta su condición de propietario de los mismos para que venga obligado a cotizar por tal concepto a la Seguridad Social Agraria; sin que tampoco pueda existir el temor de que se produzca una duplicidad en el pago de sus cuotas con respecto a ambos regímenes, éste especial 
y el general de los Seguros Sociales, dado que no es así, pues su respectiva cotización se refiere a una distinta actividad empresarial: por un lado, la correspondiente a la explotación agraria de las fincas, y de otro, la explotación industrial de los diversos productos y aprovechamientos de los montes, como resina, madera, leña, ganadería, etc., al igual que en cualquier otro negocio incluido dentro del régimen general, puesto que entonces se trataría de explotaciones perfectamente diferenciables $y$, por consiguiente, con independencia de las aportaciones empresariales efectuadas a uno y otro de los Seguros Sociales; y aun cuando en ocasiones pueda coincidir su pago en el mismo sujeto pasivo, para nada afecta a dicha duplicidad esta circunstancia, pues, aunque estuviere obligado a cotizar por ambos regímenes, lo sería por distintas modalidades de dicha Seguridad Social, lo que vendría a descartar toda idea de un doble pago por tal concepto.

Considerando: Que no se niega que en todos ellos es preciso el binomio empresario-trabajador, aunque el concepto de aquél, como puede ocurrir con este último, no se identifique en todos los casos correspondientes a los distintos Seguros Sociales, dependiendo, por tanto, del sistema adoptado para el cobro de las cuotas y su consecuencia objetiva a través de la base contributiva procedente, y sin que tampoco puedan tener los términos explotación y empresa agraria, referidos a este especial seguro, idéntico significado y carácter que el que es usual y común de los mismos, así como también esa posible repercusión en algunos sưpuestos a los, en definitiva, gravados con este último, constituyen rasgos tan destacados y diferenciales de los Seguros Sociales en general que, sin alterar los principios que informan a todos ellos, le confieren una especial regulación y un distinto tratamiento en ciertos aspectos más en consonancia con su específica función, que fácilmente puede originar esa supuesta antinomia que carece de toda existencia real con las citadas sentencias, las que, por consiguiente, no ofrecen discrepancia esencial entre ellas.

\section{ANALISIS DE LA SENTENCIA DE 23 DE MARZO DE 1973}

Como ya ha sido dicho, de las dieciocho sentencias emanadas del Tribunal Supremo, relativas al pago por los Ayuntamientos de la Cuota Patronal de la Seguridad Social Agraria, una y sólo una declara la existencia de tal obligación. Esta es la sentencia de 23 de marzo de 1973, cuyos argumentos creemos- que vale la pena analizar brevemente.

En su segundo Considerando, la sentencia plantea correctamente el problema: se trata de saber si a la vista del artículo 46 de la Ley de 31 de mayo de 1966 (artículo que, como sabemos, tiene su exacto paralelo en la Ley vigente) los obligados al pago de la Cuo- 
ta Empresarial son todos los sujetos pasivos de la Contribución Territorial o sólo los empresarios comprendidos en el artículo 4. ${ }^{\circ}$ de dicha Ley, que define aquéllos como los titulares de explotaciones agrarias.

Repetimos que el Tribunal Supremo ha mantenido en las restantes catorce sentencias la segunda tesis. En esta que ahora se comenta mantiene aisladamente la tesis primera en base a los argumentos siguientes:

a) La explotación de los montes, en definitiva, recae en beneficio de los Ayuntamientos propietarios. Fácilmente se comprende que el argumento no puede ser más deleznable. El hecho de que el producto de los montes vaya a parar a manos de los Ayuntamientos no tiene nada que ver con el dato del pago de las primas de los riesgos que en los montes se producen. Lo que se trata es saber si el Ayuntamiento debe o no pagar cuando por no ser titular de la explotación no depende de él ningún asegurado. La prueba de lo erróneo de este argumento está en que tal como se demostró en estudio publicado por el Instituto de Estudios de Administración Local y dirigido por el profesor Martín Mateo, los Ayuntamientos están perdiendo dinero en la explotación de sus montes (ver el trabajo publicado en ciclostil bajo el título «La situación del sector resinero y las Corporaciones locales»).

b) El Régimen de la Seguridad Social Agraria reviste un carácter especial por la específica naturaleza de la economía y explotación agraria. Sabido es que lo que prueba demasiado no prueba nada. La explotación agrícola es diferentísima de la industrial, de la comercial o de la pesquera. Pero ello no quiere decir en modo alguno que la prima de los riesgos que se corren en aquélla haya de ser pagada doblemente.

c) La Ley no fija las explotaciones en función de la mano de obra empleada, que resulta imposible de controlar. Esta aseveración no es cierta. Se han citado hasta la saciedad artículos de la Ley y del Reglamento, que demuestran el reiterado intento del legislador de lograr que las cuotas sean función del número de obreros asegurados. En todo caso, y para los adjudicatarios cuyos obreros son los que padecen los riesgos que se pretenden asegurar, las empresas que las llevan a cabo (esto es, los adjudicatarios) conocen perfectísimamente cuál es el número de obreros que en ellas trabajan. Precisamente este de las explotaciones forestales es un 
caso claro de posibilidad de determinación del «colectivo asegurado» con absoluta exactitud.

d) El carácter provisional del sistema. Tampoco este argumento quiere decir nada. El que un sistema sea provisional no quiere decir que tenga que ser injusto. Se trata simplemente de que el legislador tiene conciencia de que el sistema puede mejorar. En definitiva, dar a una norma el carácter de provisional no tiene jurídicamente el menor sentido. Por muy provisional que sea estará en vigor mientras no sobrevenga otra norma que la derogue o llegue la fecha de caducidad para su aplicación. Es exactamente lo mismo que sucede con las normas no provisionales.

e) La circunstancia de poder repercutir. Ya ha quedado demostrado que en los casos de los Ayuntamientos esta repercusión es imposible.

\section{CONCLUSION}

Los Ayuntamientos, con frecuencia, tienen montes catalogados como públicos en los cuales se efectúan, por terceros adjudicatarios, explotaciones madereras. En los montes municipales en cuestión no trabaja ni un solo obrero por cuenta de los Ayuntamientos. Todos los obreros de las empresas adjudicatarias están, como es preceptivo, asegurados. Por consiguiente, todos los riesgos laborales que puedan sufrirse en las explotaciones de los montes están ya cubiertos por el seguro que pagan dichas empresas. El pago de una nueva cuota por cubrir dichos riesgos (cuota a cargo de los Ayuntamientos) supone pagar dos veces la prima del mismo riesgo.

Queda claro que el único problema es el de evitar un doble pago y un consiguiente enriquecimiento injusto. Las sentencias del Tribunal Supremo y las de las Audiencias unánimemente (con una sola excepción en cada caso) así lo han reconocido.

$\mathrm{Si}$ estudiamos la instrumentación legal creemos que el meollo del problema, desde el punto de vista del doble pago, está constituido por el artículo 44 del Texto refundido de 23 de julio de 1971 y los artículos 25 a 28 de su Reglamento de 23 de diciembre de 1972.

En efecto, del citado artículo 44, 3, se deduce que el importe de la cotización empresarial se distribuye entre los sujetos de la Contribución Territorial Rústica y Pecuaria. Pero hay que tener en 
cuenta qué quiere decir la Ley cuando utiliza el adjetivo «empresarial». Tiene forzosamente que referirse al sustantivo del que aquél deriva. Y este sustantivo viene definido en el artículo $4 .^{\circ}$, diciendo que es empresario el titular de una explotación agraria. Solamente puede referirse, pues, el artículo 44 a los titulares de explotaciones agrarias (cosa que no son los Ayuntamientos) cuando habla de "cotización empresarial».

A mayor abundamiento, el apartado $8 \mathrm{del}$ propio artículo regula la cotización de los dos riesgos más importantes (accidentes y enfermedades profesionales) y de ellas dice que se efectuará separadamente por cada empresario.

Pues bien, el grupo de artículos citados del Reglamento aclara lo anterior y nos dice que «la cotización de cada empresario al Régimen de Accidentes y Enfermedades Profesionales se efectuará de conformidad con las tarifas... sobre las remuneraciones que efectivamente perciban los trabajadores» (art. 25).

Y el artículo 27 se refiere a «la cotización por contingencias que no sean las de accidentes y enfermedades profesionales... se distribuirá entre los sujetos pasivos de la Contribución».

Pues bien, ya hemos dicho que el concepto «empresarial» sólo puede derivarse del concepto empresario y que éste es lo que el artículo $4 .^{\circ}$ de la Ley dice.

Pero aun suponiendo a efectos dialécticos que no fuera así, lo que es evidente es que sólo podría hablarse de identidad entre propietario y empresario para la cotización de contingencias que no sean las de accidentes y enfermedades profesionales (es decir, las contingencias mínimas). $\mathrm{Y}$ es evidente también que la cotización importante, es decir, la de accidentes y enfermedades viene regulada por el artículo 25 del Reglamento, que para nada habla de los sujetos pasivos de la Contribución Territorial.

Creemos que hasta ahora nadie, ni la doctrina, ni la jurisprudencia, se ha hecho eco de la anterior distinción. Y, sin embargo, es esencialísima. Solamente hablan las normas de los «sujetos pasivos de la Contribución Territorial» cuando se refieren a las contingencias que no sean accidentes o enfermedades profesionales. Y solamente en ese caso.

De ahí que sostengamos que mientras la Seguridad Social no distinga con los estudios que se anuncian a nivel reglamentario entre una y otra fracción de la cuota patronal, no puede imponer a los Ayuntamientos el pago de cuota alguna. 


\section{RESEÑA DE SENTENCIAS}

SUMARIO: I. ACTO ADMINISTRATIVO: NULIDAD DE ACTO MUNICIPAL. II. BIENES: 1. CAMINO VeCINAL: RECUPERACIÓN ADMINISTRATIVA. 2. RECUPERACIÓN aDMINISTRaTIVA: CONDICIONES PARA ELlO.-III. CON! TRATACION: 1. CONCURSO INDEBIDAMENTE DECLARADO DESIERTO. 2. MODIFICACIÓN DE OBRA CONTRATADA. 3. REVISIÓN DE PRECIOS.-IV. EXPROPIACION FORZOSA: 1. DERECH O ARRENDATICIO DE LOCAL DE NEgoCIOS: CONCEPTOS A INDEMNIZAR. 2. JURADOS DE EXPROPIACIÓN: VALOR DE SUS RESOLUCIONES. 3. JUSTIPRECIO: PlaNES DE VIVIENDA Y URBANISMO. 4. JUSTIPRECIO: TERRENOS EN PARTE EDIFICABLES Y EN PARTE NO EDIFICABLES. 5. JUSTIPRECIO: TERRENO DESTINAdO A VIALES. 6. RETASACIÓN.-V. FUNCIONARIOS: 1. DePOSITARIO NO PERTENECIENTE a CUERPO NaCIONAL: RETRIBUCIONES. 2. EVENTUALES: NO SON INAMOVIBLES. 3. EVENTUALES: NOMBRAMIENTO SIN LA SIMULTÁNEA CONVOCATORIA. 4. DERECHOS PASIVOS: ACTUALIZACIÓN DE PENSIÓN. 5. DERECHOS PASIVOS: ACTUALIZACIÓN: OUINQUENIOS. 6. DERECH OS Pasivos: aCtUalización: QUiNQUenios. 7. Derech OS Pasivos: actualización: ouinguenios. 8. DERECH OS PASIVOS: aCTUALIZACIÓN: QUINQUENIOS DEL 15 POR 100. 9. DERECHOS PASIVOS: ACTUALIZACIÓN DE PENSIÓN DE VIUdEDAD. 10. DERECHOS PASIVOS: SERVICIOS EVENTUALES. 11. VIUDEDAD PRODUCIDA POR FUNCIONARIO JUBILADO EN EL AÑO 1954.-VI. HACIENDAS LOCALES: 1. ARbitrio por edificación deficiente. 2. Arbitrio de plusvalfa: NOtificación obligada al enajenante. 3. ARbitrio de plusvalfa: teRrenos sujetos al mismo. 4. ARbitrio de plusvalfa: terrenos aGrícolas. 5. Arbitrio de plusvalfa: tasa de equivalencia: terrenos de CoNGREGACIÓN RELIGIOSA DEDICADA A LA ENSEÑANZA RETRIBUIDA. 6. CONTRIBUCIONES ESPECIALES: POR AUMENTO DE VALOR. 7. CONTRIBUCIONES ESPECIALES: POR ALUMBRADO. 8. CONTRIBUCIONES ESPECIALES: PAVIMENTACIÓN, ALCANTARILlado Y OTRAS. 9. CONTRIBUCIONES ESPECIALES: IMPUGNACION. 10. LICENCIA FISCAL DEL IMPUESTO INDUSTRIAL: CENTRAL HIDROELÉCTRICA. - VII. JURISDICCION CONTENCIOSO-ADMINISTRATIVA: 1. Dictamen de Letrado. 2. Legitimación activa de MUNICIPIO AFECTADO POR UNA AUTOPISTA.-VIII. MUNICIPIOS: INCORPORACIÓN POR NECESIDAD O CONVENIENCIA ADMINISTRATIVA. - IX. POLICIA MUNICIPAL: 1. LICENCIA: HORNOS DE PAN: COMPETENCIA Municipal. 2. Multas: prescripción. 3. Piedras que amenazan Caer 
SOBRE UN POBLADO.-X. PROCEDIMIENTO ADMINISTRATIVO: 1. Dictamen de Letrado previo al eJercicio de acciones por las CoRPORACIONES locales. 2. NOTIFICACIÓN AL PRIMER FIRMANTE DE UN ESCRITO FIRMADO POR VARIOS. 3. RECURSO DE REPOSICION Y NO MERA DENUNCIA de NOTIFICACIÓN DEFECTUOSA.-XI. SANIDAD: 1. Servicio DE DESINFECCIÓN Y DESINSECTACION: COMPETENCIA MUNICIPAL. 2. SERVICIOS FÚNEBRES: COMPETENCIA.-XII. SERVICIOS: MUNICIPALIZACION: REVISIÓN DE TARIFAS: aPROBACIÓN. - XIII. URBANISMO: 1. ACcIÓN pública de la Ley del Suelo. 2. Expropiación: falta de Planes parCiales. 3. Planes Generales: No pUeden formularlos las ENTIDades LOCALES MENORES.-XIV. ZONA MARITIMO-TERRESTRE: LINDERO CON EL MAR.

\section{ACTO ADMINISTRATIVO}

\section{NULIDAD DE ACTO MUNICIPAL}

Aun comulgando la Sala con la naturaleza de la nulidad que postula el Ayuntamiento de Monforte de Lemos, la misma, si bien pudo ser invocada por el particular en cualquier tiempo, no estando sujeto a plazo de prescripción o caducidad alguna - sentencias del Alto Tribunal de 25 de noviembre de 1965,14 de mayo y 15 de noviembre de 1965 , 23 de diciembre de 1966 y 13 de mayo de 1967-, nunca pudo ser recogida de oficio por la Administración central más que en el supuesto del artículo 109 de la Ley de 17 de julio de 1958, y para ello previa audiencia del Consejo de Estado, supuesto que jamás pudo darse en el ámbito local, en el cual el único camino para anular los acuerdos creadores de derechos es el cauce de la lesividad - sentencias del Tribunal Supremo de 14 de enero de 1965 y 22 de noviembre de 1966-, o bien la denuncia del particular y la incoación por la Corporación en cuestión del correspondiente expediente anulatorio, el que se instruirá con audiencia del afectado por ella - sentencias del Tribunal Supremo de 2 de julio de 1964 y 27 de mayo de 1968-, por todo lo cual la nulidad del acuerdo de 28 de mayo de 1952 no podía realizarse ni por la concesión que se dice celebrada en exclusiva a favor de don Dictino S., en cuanto se estipuló la base 26 , que le prohibía inmiscuirse en lo que fue objeto del acuerdo de 28 de mayo de 1952, ni tampoco por la nulidad in radice del acuerdo de 1952, en cuanto las Corporaciones locales no pueden anular por sí de oficio sus actos creadores de derechos, sino a través del cauce de la lesividad y siempre que no hubieran pasado cuatro años desde que se adoptaron -artículo 369 de la Ley de 24 de junio de 1955, artículo 56 de la Ley de 27 de diciembre de 1956 y artículo 37 de la Ley Jurídica de la Administración del Estado de 26 de julio de 1957-, criterio corroborado por las sentencias del Tribunal Supremo de 27 de febrero de 1964, 24 de diciembre de 1966 y 13 de octubre de 1966. (Sentencia de 8 de mayo de 1974, Ar. 2.341). 


\section{BIENES}

\section{Camino vecinal: RECUPERACIÓN ADMinistrativa}

Ninguna duda cabe de que los caminos vecinales, aunque fueren simples sendas para peatones, están sujetos a la posibilidad de su reivindicación en vía administrativa, según afirma la sentencia dictada por la Sala 4.a del Tribunal Supremo el 30 de octubre de 1965, cuando recuerda que "como declararon las sentencias de la Sala de 28 de abril de 1960, 5 de julio de 1961 y 10 de diciembre de 1963, estos caminos rurales de carácter rudimentario y carentes de firme que comunican pequeños núcleos urbanos o simples zonas de cultivo o aprovechamiento dentro del mismo término municipal no pueden ser excluidos de la protección que les aseguran los artículos 370 y 404 de la Ley de Régimen local y 55 del Reglamento de Bienes de las Entidades locales, dejándolos a merced del usuario, que de los mismos pretende apropiarse con perjuicio de los demás». Tampoco obsta a la reivindicación, tratándose de un camino público, el que haya transcurrido algo más de un año desde la usurpación, pues en tal supuesto no existe un plazo limitativo de su defensa por la Administración como reconoce la sentencia también dictada por la Sala 4. ${ }^{a}$ dei Tribunal Supremo de 20 de marzo de 1969, y es que el artículo 55 del Reglamento de Bienes, que a tal autoriza, no es contrario al artículo 404 de la Ley de Régimen local, sino simple desarrollo del 188 de la misma Ley, declaratorio de la condición extra comercium de los bienes de dominio público. (Sentencia de 10 de junio de 1974, Ar. 2.657).

\section{RECUPERACIÓN ADMINISTRATIVA: CONDICIONES PARA ELLO}

Considerando: Que los artículos 404 de la Ley de Régimen local, 344 del Reglamento de Organización, Funcionamiento y Régimen jurídico de las Corporaciones locales y 55 del Reglamento de Bienes atribuyen a las Corporaciones locales la facultad de recobrar por sí la tenencia de sus bienes, en todo tiempo cuando se trata de bienes de dominio público y dentro del plazo de un año cuando se refieren a bienes patrimoniales, que se ha venido llamando interdicto administrativo o interdicto propio, quizá porque a semejanza de los procedimientos interdictales de la Ley de Enjuiciamiento supone únicamente una recuperación de la posesión despojada de un bien, sin decidir nada acerca del derecho de propiedad o de otros pretendidos derechos sobre los bienes; por su parte, la Jurisprudencia ha venido perfilando el alcance y precisando la interpretación adecuada de los preceptos antes señalados, habiendo declarado que, dada la naturaleza privilegiada y el carácter estrictamente posesorio de la facultad de recuperación, administración 
que los citados preceptos conceden, su ejercicio viene subordinado a una prueba completa que demuestre el uso público de esos terrenos y el hecho de la usurpación - sentencias del Tribunal Supremo de 5 de octubre de 1965, 20 de marzo de 1969, 27 de enero, 4 de julio, 25 de septiembre y 30 de noviembre de 1970-; añadiéndose en la de 18 de enero de 1967 que es preciso que esté perfectamente delimitado lo que es público y privado, y en la de 18 de junio de 1968, que es necesario acreditar en forma previa y suficiente esa naturaleza, sin que sea suficiente una vaga suposición, y las de 29 de marzo de 1969 y 25 de septiembre de 1970, que los Ayuntamientos no pueden discutir derechos privados sobre terrenos si no tienen elementos suficientes para negarlos, a fin de no involucrar cuestiones civiles que son de la competencia de la jurisdicción ordinaria, ante la que la Administración debe pretender su derecho. (Sentencia de 6 de junio de 1974, Ar. 3.206).

\section{CONTRATACION}

\section{CONCURSO INDEBIDAMENTE DECLARADO DESIERTO}

Considerando: Que según se dice en el dictamen del llamado aJurado calificador» del concurso para la concesión del servicio público de transportes, dictamen que hizo suyo el Ayuntamiento pleno en el acuerdo recurrido, y se reconoce en el informe que a tenor del artículo 595 de la Ley de Enjuiciamiento civil ha emitido en este proceso, el Alcalde de Premiá de Mar, la decisión de declarar desierto el concurso y abrir, después de los estudios y aprobación de tarifas que se dicen en aquél, otro concurso responde a que se estimó por aquel órgano calificador y se aceptó por la Corporación, que debió preceder una aprobación de las tarifas por el Gobernador civil, tesis que se sustenta acudiendo al artículo 18 de la Ley de 23 de julio de 1966, pero no, como se reconoce en términos que alejan toda duda en aludido informe, en que las proposiciones presentadas incumplieran las condiciones del pliego, pues, por el contrario, se ha afirmado por la Administración que todas las proposiciones se ajustaban a las condiciones del pliego, de lo que se infiere que la Corporación, al adoptar el acuerdo impugnado, se apartó de lo que dispone el artículo 40,5, del Reglamento de Contratación de las Corporaciones locales, aplicable a este concurso - con carácter supletorio del Reglamento de Servicios-, según dice el artículo 116, número 1, de este Reglamento, pues si bien faculta a la Administración para declarar desierto el concurso subordina esta decisión a que ninguno de los concurrentes cumpla las condiciones del pliego.

Considerando: Que, sin embargo, eludido por el órgano calificador el juicio que debió llevar a la elección de la mejor proposición, no nos corresponde que, supliendo la apreciación que no hizo aquél, nos pronunciemos por uno de los concursantes, pues, declarado desierto el 
concurso, falta el juicio del Jurado y, por ende, que podamos entrar a revisarle en la medida admitida por el Derecho; y si esto es así y el recurrente no puede invocar más que un interés, tutelado por el Derecho, a que se valore la oferta de contrato que ha elevado, y en su caso, si es la mejor, se le adjudique el servicio, faltan los presupuestos para la pretensión de indemnización que también ha ejercitado el recurrente, debiendo, por tanto, estimarse la de anulación, mas no la de reconocimiento de un derecho a que se le adjudique el servicio y la de indemnización, y todo sin una condena en costas. (Sentencia de 18 de mayo de 1974, Ar. 2.514).

\section{MODIFICACIÓN DE OBRA CONTRATADA}

Considerando: Que en base a los precedentes fundamentos jurídicos, la Sala estima que el proyecto adicional del centro o colegio libre de Segunda Enseñanza del Ayuntamiento de San Roque constituye simple modificación de la obra adjudicada en la subasta inicial que pudo ser impuesta por la Administración (aunque en este caso fue voluntariamente aceptada por el contratista), en el ejercicio de las facultades afectantes a la inmutabilidad de dichas prestaciones contractuales establecidas en el artículo 54 del Reglamento de Contratación de las Corporaciones locales, sin que tal modificación implique la alteración de las estipulaciones contenidas en el pliego de condiciones de la subasta, $y$, por tanto, ha de regir para los precios establecidos en el citado proyecto adicional la baja del 14,30 por 100 prevista en aquellas estipulaciones, por lo que el Ayuntamiento de San Roque actuó legalmente al retener la fianza en tanto no se proceda por el contratista, señor L. M., a la devolución de las cantidades percibidas excesivamente y con plena infracción contractual, al no haber consentido se dedujese el expresado 14,30 por 100 de la entrega parcial, que ampara la certificación de obras unida al folio 2 del expediente administrativo. (Sentencia de 8 de mayo de 1974, Ar. 2.342).

\section{REVISION DE PRECIOS}

Interesa leer la amplia exposición que hace el Tribunal analizando la posible contradicción de las sentencias de 15 de enero de 1971 y 5 de enero de 1972, para sentar su tesis de la derogación del artículo 57, I, e), del Reglamento de Contratación. Dice así:

Con mayor exigencia aún, ha de entenderse abolida la facultad revisora, autorizada en el apartado a) del artículo 57, 1, del Reglamento, por cuanto la tesis de esta sentencia establece categóricamente que dicha facultad revisora, acordada en este inciso para la Administración 
local, en consecuencia directa e inmediata de lo estatuido para la Administración central en la Ley de 17 de julio de 1945, en aras del principio que propugna la igualdad de trato entre ambas esferas, pues la contratación que a ellas afecta constituye dos manifestaciones de una misma actividad jurídica, lo cual nos conduce a la conclusión final de que no es consecuente ni lógico admitir en la contratación local un principio revisorio, que en su conformación jurídica originaria está derogado para la Administración central, y ello en defensa de un principio de igualdad de trato entre ambas esferas, que de este modo sí quedaría conculcado efectivamente, toda vez que la reglamentación revisora actual de la actividad contractual administrativa del Estado se presenta con un carácter más restringido en su contenido y alcance, en la que se disminuye su entidad y se aumenta el control de la misma, pues en todo caso siempre nos encontraríamos con que el argumento principal de la demanda no es consecuente en su lógico desarrollo, supuesto que si se invoca y admite que el Decreto de 25 de febrero de 1955 ha sido derogado implícita y tácitamente por el Decreto-ley de 4 de febrero de 1964, igualmente habría de aceptar, como parece deducirse de la referida sentencia de 15 de enero de 1971, todos los significados y objetivos de este último Decreto-ley, o sea, el derogatorio y el implantatorio que encierra su contenido, por lo que, en su consecuencia, siempre habrían de operarse en el futuro sus propias fórmulas revisoras, pero en modo alguno las definitivamente derogadas del artículo 57, I, e), del Reglamento de Contratación de las Corporaciones locales, a cuyo dictado pretende fiar la demanda el éxito del recurso. (Sentencia de 17 de mayo de 1974, Ar. 3.103).

\section{EXPROPIACION FORZOSA}

\section{DERECHO ARRENDATICIO DE LOCAL DE NEGOCIOS: CONCEPTOS A INDEMNIZAR}

Considerando: Que en consecuencia de cuanto antecede, la indemnización por la extinción del Derecho arrendaticio del local de negocio y traslado de la industria de restaurante instalada en el inmueble de la referida parcela 350, queda establecida en los términos siguientes: a) Derechos de inspección, licencia de apertura y arbitrios municipales: 15.000 pesetas; $b$ ) Gastos de acometidas de luz y fuerza, agua y teléfono en el nuevo emplazamiento: 48.000 pesetas; $c$ ) Gastos de traslado: 47.400 pesetas; $d$ ) Gastos de sustitución o reinstalación en el local a que se traslade y reposición de elementos de producción: 450.000 pesetas; $e$ ) Indemnización al personal: 306.000 pesetas; $f$ ) Pérdidas de beneficios por cierre de la industria: 600.000 pesetas; $g$ ) Merma de clientela: 280.000 pesetas, y $h$ ) Indemnización por mayor renta: 168.000 pesetas; cantidades cuya suma asciende a 1.914 .400 pesetas, cuya suma se in- 
crementa con la cantidad que corresponda por el 5 por 100 por premio de afección, conforme a lo dispuesto en el artículo 47 del Reglamento de la Ley de Expropiación forzosa, o sea, 95.720 pesetas, lo que arroja un total de 2.010.120 pesetas. (Sentencia de 5 de junio de 1974, Aranzadi 2.596$)$.

\section{JURADOS DE EXPROPIACIÓN: VALOR DE SUS RESOLUCIONES}

Si de los Jurados Provinciales de Expropiación se ha podido decir, multitud de veces, que son merecedores de confianza, en su misión específica valorativa, por su acertada composición, la preparación de sus miembros, su independencia y experiencia -sentencias de 2 y 12 de marzo de 1959, 6 de octubre de 1960, 28 de junio de 1961, 5 de marzo de 1962, 20 de mayo de 1963, 27 de enero, 21 de febrero y 20 de marzo de 1964, 11 de abril de 1966, 15 de enero, 13, 26 y 30 de noviembre de 1968, 31 de enero de 1969, entre otras-, no es menos evidente que esta postura no ha sido impedimento para poder reconocer que una vez interpuesto recurso contencioso-administrativo, a la jurisdicción correspondiente, con plenitud de competencia, la fijación del valor de lo expropiado, negando a los acuerdos de los Jurados fuerza vinculante y poder discrecional -sentencias de 14 de abril y 3 de diciembre de 1958, 22 de noviembre de 1960, 18 de junio de 1963 y 7 de febrero de 1968-. (Sentencia de 8 de junio de 1974, Ar. 2.647).

\section{JUSTIPRECIO: PLANES DE VIVIENDA Y URBANISMO}

Que conforme a lo dispuesto en el artículo 102 del Reglamento expropiatorio, 85 y 93 de la Ley del Suelo, en relación con el artículo 1. y concordantes de la Ley de 21 de julio de 1962, la valoraciones de terrenos necesarios para la ejecución de planes de vivienda y urbanismo, cualquiera que sea la entidad expropiante, se ajustará a lo dispuesto en la Ley del Suelo, concretando que en tales expedientes no será de aplicación el artículo 43 de la Ley de Expropiación forzosa, precepto que se reitera en el artículo 5. del Decreto de 21 de febrero de 1963, debiendo verificarse con arreglo a los indices municipales que a tal fin hayan sido aprobados por el Ministerio de la Vivienda conforme se infiere además del artículo 1. 0 del Reglamento de 21 de febrero de 1963, constituyendo al dictado de estas disposiciones, el índice, un modo de valoración de legal cumplimiento que, conforme a la declaración formulada en el número 5 del artículo $2 .^{\circ}$ de la Ley de 21 de julio de 1962, la valoración de los terrenos en los respectivos índices tendrá la consideración de justo precio, sin que, de acuerdo con el número 7 del propio artículo 2..$^{\circ}$, pueda impugnarse el acto de la tasación individualizada si no es por defecto del procedimiento o por aplicación de los índices aprobados. (Sentencia de 5 de junio de 1974, Ar. 2.592). 


\section{JUSTIPRECIO: TERRENOS EN PARTE EDIFICABLES Y EN PARTE NO EDIFICABLES}

ConsIDERANDo: Que siendo evidente la existencia de estas diversas circunstancias dentro de la finca expropiada - no bien apreciadas por el Jurado ni por la Sala de Audiencia-, derívase la consecuencia, al objeto de obtener su precio real, de distinguir de manera prudente y equitativa un valor para la parte edificable y otro valor para el resto de la finca excluido de la posibilidad de edificación y, por éste, de alcanzar cifra similar a la de aquélla. (Sentencia de 24 de junio de 1974, Aranzadi 2.756).

\section{JUSTIPRECIO: TERRENO DESTINADO A VIALES}

Pero no teniendo en cuenta, según efectuó el Jurado en sus acuerdos, dicho destino vial asignado por el aludido plan, y si la propia condición del terreno con anterioridad al mismo, de evidente cualidad urbana por su situación y servicios que le encuadraban en el concepto de solar a tasar, en principio, con sujeción al artículo 38 de la Ley expropiatoria, en el valor que hubiese asignado para los efectos del arbitrio municipal sobre incremento de valor de los terrenos, aumentado en un 10 por 100 , sin que tal naturaleza pueda ser alterada, a efectos valorativos, por consecuencia de que en virtud de la planificación parcial expresada pasará a ser utilizado como vial, pues entenderlo de otro modo supondría atribuir al planeamiento urbanístico facultades realmente confiscatorias al establecer un cambio de destino con la trascendencia de desconocer que la valoración pertinente es la que determina la condición urbanística que antes correspondía a la finca y no su nuevo destino, como tiene declarado con reiteración la jurisprudencia de esta Sala en numerosas sentencias, entre otras las de 9 de febrero de 1972 y 26 de septiembre de 1973, lo que conduce a rechazar ese motivo de apelación y confirmar en dicho extremo la sentencia recurrida. (Sentencia de 2 de julio de 1974, Ar. 3.078).

\section{RETASACIÓN}

Considerando: Que de los artículos 35-3, 48, 50 y 58 de la Ley de Expropiación forzosa y 74 de su Reglamento, resulta que la valoración caduca a los dos años de haberse efectuado administrativamente si no se ha hecho efectiva o consignado, sin que le afecte la revisión jurisdiccional que ha de referirse siempre al acto que es objeto de tal revisión, por lo que lo fundamental para determinar si puede producirse o no la nueva evaluación no es la existencia de procesos jurisdiccio- 
nales y sentencias dictadas en los mismos, sino si la Administración expropiante o el beneficiario de la expropiación ha cumplido su obligación de consignar o pagar el precio fijado en vía administrativa antes de transcurrir dos años. (Sentencia de 29 de mayo de 1974, Ar. 2.472).

\section{FUNCIONARIOS}

\section{Depositario no perteneciente a Cuerpo Nacional: RETRIBUCIONES}

Considerando: Que ya esta Sala en las sentencias de 6 de octubre de 1966 y 22 de junio de 1968, al examinar casos idénticos al ahora enjuiciado, resolvió que los Depositarios de fondos en propiedad -condición no negada al demandante-, aun no perteneciendo al Cuerpo general, tienen derecho, visto lo dispuesto en los artículos $1 .^{\circ}$ y $3 .^{\circ}$ de la Ley 10/1963, de 20 de julio, a los emolumentos denominados sueldo base (según el grado asignado a su cargo), retribución complementaria, aumento quinquenal, así como a las pagas extraordinarias, sin que del contenido de dicho artículo $3 .^{\circ} \mathrm{ni}$ del contexto general o normativa vigente se deduzca que tales emolumentos únicamente puedan disfrutarlos los funcionarios pertenecientes al Cuerpo general; antes, por el contrario, se utiliza la expresión de que la asignación de grado se verifica "para cada cargo o puesto de trabajo», por lo que ha de concluirse que si la plaza de Depositario del Ayuntamiento de Ribadesella tiene señalado el grado retributivo 18 y está ocupada en propiedad, disfrutará su titular de los emolumentos correspondientes a aquél, abstracción hecha de su pertenencia o no al tan repetido Cuerpo general. (Sentencia de 10 de junio de 1974, Ar. 2.650).

\section{EvENTUALES: NO SON INAMOVIBLES}

Considerando: Que el hecho de que la relación existente entre las recurrentes y la Diputación tenga carácter administrativo -como lo reconoció en este caso la jurisdicción laboral- no otorga a aquéllas, sin más, la pretendida inamovilidad; pues ésta sólo la alcanzan los funcionarios en propiedad o aquellos que careciendo de tal carácter la normativa vigente expresamente les reconoce tal seguridad o permanencia en el servicio; circunstancia que no concurre en los ahora recurrentes; siendo inoperante, al respecto, el que las interesadas -como ellas alegan- lleven mucho más de seis meses de servicios; pues es obvio que en nuestro Derecho sobre funcionarios públicos no es medio de adquirir la titularidad en propiedad, la usucapión; como se puso de relieve ya por la Jurisprudencia - sentencias de 12 de mayo de 1947, 20 de junio de 1949, 3 de abril de 1952, 3 de octubre de 1953, 11 de mayo 
de 1955,30 de junio de 1959, 5 de octubre de 1960, 1 de diciembre de 1961 y 7 de diciembre de 1973 entre otras-. (Sentencia de 3 de junio de 1974, Ar. 2.586).

\section{EvENTUALES: NOMBRAMIENTO SIN LA SIMULTÁNEA CONVOCATORIA}

Se limitan, en lo sustancial, las impugnantes a basar la nulidad pretendida de los Decretos de la Diputación provincial de Madrid, fechados el 14 de junio de 1967, en que, a pesar de ser nombradas las que accionan en 1 de agosto de 1964, de acuerdo con lo dispuesto en el apartado 3 del artículo 9. de la Ley de 20 de julio de 1963, no se convocaron "al propio tiempo», por la Corporación citada, las pruebas selectivas a que alude tal precepto; pero es lo cierto que el designio evidente del legislador fue evitar que se efectuasen nombramientos sin utilizar los procedimientos legalmente establecidos (oposición, concurso, concurso-oposición) en garantía de la idoneidad profesional de los elegidos $\mathrm{y}$, por tanto, de cualquier modo la dilación en que pudiera haber incurrido la Diputación provincial de Madrid en orden a la convocatoria a que se alude en el número 3 del citado artículo 9.0, no ocasionaría ello la nulidad invocada del cese acordado de las ahora recurrentes, sino que implicaría la ilegalidad de su nombramiento, con lo cual quedaría sin base alguna la petición de reingreso. (Sentencia de 3 de junio de 1974, Ar. 2.586).

\section{DERECHOS PASIVOS: aCTUALIZACIÓN DE PENSIÓN}

Considerando: Que el artículo 10, 2, de la Ley 108 de 20 de julio de 1963 excluye de actualización «las pensiones que resulten superiores - iguales a la dotación de los sueldos», que los causantes habrían consolidado en activo, y que la regla cuarta de la Orden de 22 de abril de 1964 desarrolla lo preceptuado en aquél, estableciendo que estarán exceptuadas de actualización: B) Las pensiones que al actualizarlas resulten superiores o iguales a los nuevos sueldos con los quinquenios y pagas extraordinarias correspondientes en cada caso. En este supuesto, la actualización quedará limitada al referido importe del sueldo regulador.

Considerando: Que a diferencia de lo preceptuado en el artículo 10 de la Ley 108 de 1963 y en la Orden de 22 de abril de 1964, el Decreto 3.083 de 15 de octubre de 1970 , regulador de la actualización de pensiones causadas con anterioridad a 1 de enero de 1969, dejó excluida de dicha actualización, en armonía con lo previsto en el Decreto de 19 de diciembre de dicho año, «las pensiones que se hubieren concedido al amparo de condiciones más beneficiosas que las establecidas en las 
normas estatutarias de la Mutualidad, cuando dichas condiciones resulten de derechos legítimamente adquiridos con anterioridad, en virtud de leyes, reglamentos generales, normas o acuerdos singulares, aprobados por Entidad local afiliada en la que el causante haya prestado sus servicios», y precisando que constituyen, entre otras condiciones más beneficiosas: $d$ ) Porcentaje del haber regulador determinante de la pensión que sea superior al de las normas estatutarias, preceptuándose que «se pronunciará de oficio, que los titulares de pensiones determinadas en virtud de las condiciones más beneficiosas, optan por acogerse a la actualización que se establece en este Decreto, sujetándose a los preceptos estatutarios de la Mutualidad, con renuncia de todas las peculiaridades de su situación anteriorn, a menos que el pensionista manifieste por escrito ante la Mutualidad que desea seguir acogido al régimen anterior, y estableciéndose expresamente en la Orden de 2 de diciembre de 1970 la incompatibilidad de los sueldos del Decreto-ley 23 de 1969 y la reserva de las condiciones más beneficiosas en materia de derechos pasivos que se amparen en disposiciones o acuerdos anteriores a dicho Decreto-ley. (Sentencia de 20 de junio de 1974, Aranzadi 2.737).

\section{DeReChos Pasivos: actualización: QUINQUENIOS}

El Tribunal Supremo mantiene la resolución del Ministerio de la Gobernación favorable al cómputo de quinquenios en el supuesto a que se refiere el Considerando que sigue:

Considerando: Que el causante, que ingresó como funcionario del Ayuntamiento de Valencia el 1 de septiembre de 1924 y cesó por jubilación al cumplir la edad reglamentaria el 1 de febrero de 1950, computándosele veinticinco años de servicios, falleció el 23 de octubre de 1967, solicitando su esposa la pensión de viudedad actualizada, señalándole la MUNPAL la de 1.517 pesetas a cargo de dicha Corporación y no computándole quinquenios acumulativos, frente a cuyo acto administrativo recurrió en alzada la interesada ante el Ministro de la Gobernación, que en su resolución estimó la reclamación, declarando el derecho de la recurrente a obtener pensión de viudedad con cargo a la Mutualidad, para cuyo cálculo se acumularía al haber regulador el importe de cinco quinquenios. (Sentencia de 25 de mayo de 1974, Ar. 2.390).

\section{DERECHOS PASIVOS: ACTUALIZACIÓN: QUINQUENIOS}

CONSIDERANDo: Que la cuestión a resolver en el presente recurso se reduce a decidir si el régimen de aumentos graduales o quinquenios, que debe aplicarse al actualizar la pensión de orfandad de doña Ma- 
ría A. I., causada por la defunción de su padre, funcionario del Ayuntamiento de San Sebastián, ocurrida en 7 de mayo de 1938, es, como señala la resolución recurrida, el establecido en el artículo $10^{\circ}$ de la Ley $108 / 63$, o, como pretende la MUNPAL, entidad recurrente, el que estuviera vigente en 23 de marzo de 1932, fecha en que cesó en el servicio dicho causante.

ConsIDERANDo: Que dicha entidad recurrente invoca para que no se reconozcan los quinquenios, que el número 2 del artículo 10 de la Ley 108/63, de 20 de julio, establece que «para la actualización de los derechos pasivos se adoptará como sueldo regulador en cada caso el que los causantes habían consolidado en activo con arreglo a la legislación vigente a la sazón», y que en la fecha del fallecimiento del causante -23 de marzo de 1932 - no existían los aumentos graduales del sueldo por quinquenios, ya que los mismos se establecieron por primera vez en la Ley de 31 de octubre de 1935, pero en dicha cita de la demanda se ventila el contenido del alegado artículo 10 de la Ley 108/63, pues a continuación, de la parte del mismo invocada que queda entrecomillada, el artículo expresa «si los cargos o puestos de trabajo que desempeñaron hubieran estado dotados con los emolumentos que ahora correspondan", y, por tanto, para la actualización de la pensión a que afecta este recurso han de tenerse en cuenta los aumentos quinquenales que corresponderían al causante conforme a la Ley 108/63, puesto que los mismos forman parte de los emolumentos actuales de los funcionarios de la Administración local, según se establece en el número 2 del artículo $10^{\circ}$ de la misma, o cual está corroborado por lo dispuesto en la norma 2. a, apartado I, de las que para la actualización contiene la Orden de 22 de abril de 1964, teniendo además ya declarado esta Sala en reiteradas sentencias, según las cuales, de aceptarse la doctrina de la recurrente, quedaría incumplido el espíritu informador de toda la legislación de actualización de pensiones, que pretende que, en cuanto sea posible, quienes desempeñaron el mismo empleo y con igual categoría, clase y año de servicios no reciban derechos pasivos en cuantía desigual por el simple hecho de haberlos prestado en distintas épocas. (Sentencia de 12 de junio de 1974, Ar. 2.711).

\section{DERECHOS PASIVOS: ACTUALIZACIÓN: QUINQUENIOS}

Considerando: Que la cuestión de fondo suscitada en este recurso contencioso-administrativo, relativa a si en la actualización de las pensiones de orfandad de doña Eugenia A. G., doña Justa I. F. y doña María Antonia M. P. han de tenerse en cuenta, para la determinación del sueldo regulador, los quinquenios correspondientes a los años de servicios de sus causantes o únicamente los computables con arreglo a la legislación vigente en la fecha de su jubilación, ha sido ya sometida al enjuiciamiento y función revisora de esta Sala, dando lugar a una doc- 
REVL-1975, núm. 186. GONZALEZ-BERENGUER URRUTIA, JOSE LUIS. LOS AYUNTAMIENTOŠ NO...

JURISPRUDENCIA

trina que, consignada, entre otras, en las sentencias de 23 de diciembre de 1966, 5 de abril de 1967, 27 de enero de 1971 y 28 de marzo de 1974, declara que, configurándose los aumentos graduales como una parte del sueldo del funcionario y eliminadas por la Ley 108 de 1963, las limitaciones impuestas por la legislación anterior han de ser computados la totalidad de los años de servicios prestados por los causantes de las pensiones. (Sentencia de 9 de mayo de 1974, Ar. 2.210).

\section{DEREChos Pasivos: ACTUALIZACIÓN: QUINQUENIOS DEL 15 POR 100}

Considerando: Que la cuestión planteada en el presente recurso se limita a dilucidar si es o no conforme a la normativa legal aplicable la pretensión del recurrente, funcionario jubilado de la Diputación de Zamora, de que al reconocerle la pensión de jubilación actualizada conforme al Decreto $3.083 / 1970$, de 15 de octubre, se le estimen los quinquenios en cuantía del 15 por 100 del haber regulador, que como derecho adquirido tenía reconocido, en base a acuerdo adoptado por la Diputación Provincial de Zamora, que fue ratificado por la sentencia de la Sala de lo Contencioso-administrativo de la Audiencia Territorial de Valladolid de 14 de diciembre de 1964, y como conforme al artículo 82 del Reglamento de Funcionarios de la Administración Local de 30 de mayo de 1952, a la Orden de 7 de junio de 1962 y al artículo $1 .^{\circ}$ de la Ley $108 / 63$, de 20 de julio, cada quinquenio de los mismos consiste en un aumento del 10 por 100 del sueldo consolidado, no ofrece duda que el recurrente disfrutaba de condiciones más beneficiosas al habérsele computado los quinquenios por respeto a sus derechos adquiridos en un 15 por 100 .

Considerando: Que en la exposición de motivos del Decreto de actualización de pensiones $3.083 / 70$ se consigna que los beneficios derivados de «derechos adquiridos» deben ser respetados y mantenidos, pero no resulta admisible que cuando el ordenamiento anterior experimente sustanciales y beneficiosas mutaciones quepa la posibilidad de escoger de cada uno las normas que se consideren más convenientes por el interesado y rechazar las restantes, y desarrollando tal principio, el apartado 2 del artículo $10^{\circ}$ del Decreto dispone que «en armonía con lo previsto en el artículo 11, 1, del Decreto 3.215/69, de 19 de diciembre, quedan excluidas de actualización las pensiones que se hubieran concedido al amparo de condiciones más beneficiosas que las establecidas por las normas estatutarias de la Mutualidad», y en el artículo 2.० del mismo Decreto se establece que se presumirá de oficio que los titulares de pensiones determinadas, en virtud de alguna condición más ventajosa, opten por acogerse a la actualización que se establece en dicho Decreto, sujetándose íntegramente a los preceptos estatutarios de la Mutualidad, con renuncia de todas las peculiaridades dimanantes de las disposiciones, actos o acuerdos que amparaban su anterior situa- 
ción, presunción que sólo por expresa manifestación del pensionista de que desea seguir acogido al régimen anterior quedará sin efecto, preceptos que son ratificados y desarrollados por las Ordenes de 2 de diciembre de 1970 y 24 de mayo de 1972. (Sentencia de 22 de mayo de 1974, Ar. 2.386).

\section{DeRechos pasivos: actualización de PENSIÓN DE VIUdEDAD}

Considerando: Que la única cuestión que ha de resolverse en esta sentencia consiste en determinar cuál es el porcentaje que corresponde aplicar a la actualización de la pensión de viudedad efectuada de conformidad con lo dispuesto en el artículo 10 de la Ley 108/63, de 20 de julio, si el señalado en la pensión inicial del 56 por 100 o el que fijan los Estatutos de la MUNPAL del 45 por 100; tanto de lo ordenado en el citado precepto como en la norma $2 .^{a}$ de la Orden del Ministerio de la Gobernación de 22 de abril de 1964, en ejecución de la citada Ley, resulta que el porcentaje aplicado primitivamente, lo mismo sea por disposiciones de carácter general que por los reglamentos o acuerdos particulares de las Corporaciones locales, ha de mantenerse, como derecho adquirido, al ser tales porcentajes reconocidos con anterioridad a la vigencia de la Ley de la Mutualidad, sin que exista ley posterior aplicable a este caso que contradiga tales disposiciones. (Sentencia de 22 de mayo de 1974, Ar. 2.385).

\section{DERECHOS PASIVOS: SERVICIOS EVENTUALES}

ConsIDERANDo: Que la cuestión suscitada en el recurso se circunscribe a decidir si, a efectos pasivos, son o no computables en cuanto a los funcionarios que fueron afiliados obligatorios a la Mutualidad Nacional de Previsión de Administración local en el momento de su constitución, como ocurre con el interesado, los servicios prestados con carácter provisional, interino, temporal o eventual, tratándose por ello de problema ya planteado en procesos tramitados anteriormente en virtud de recursos similares entablados ante esta Sala y que se han resuelto reiteradamente en sentido afirmativo, según doctrina declarada, entre otras, en sentencias de 18 de diciembre de 1968, 27 de febrero de 1969,4 de octubre y 27 y 30 de noviembre de 1972, según las cuales la disposición transitoria 2. ${ }^{a}$ de los Estatutos de la Mutualidad de 12 de agosto de 1960 reconoció excepcionalmente en su apartado $4 .^{\circ}$ a los incorporados obligatoriamente a ella en el momento de su constitución, con arreglo a lo prevenido en la Ley que la creó, como período de cotización y afiliación activa todo el tiempo de servicios computables a la Administración local, no sólo los prestados en propiedad, sino los que, con sujeción a la Orden de 2 de abril de 1964, en su apartado 5, 2, dada 
en ejecución de lo dispuesto en la Ley $108 / 63$, de 20 de julio, dieron lugar al derecho a quinquenios, es decir, los servicios prestados efectivamente día por día, bien en propiedad o con carácter provisional, interino o eventual, entre los que han de ser incluidos también los prestados con carácter accidental, según resulta de lo prevenido en la Norma $7-2$ de la Instrucción dada en Orden ministerial el 15 de octubre de 1962.

ConsIDERANDo: Que la doctrina y conclusión anteriormente expuestos no queda afectada en sentido modificativo alguno por consecuencia de lo establecido en el Decreto 3.083/70, según pretende la actora, puesto que dicha disposición no es de aplicación en el presente caso, siéndolo sólo a las pensiones que se determinen o actualicen con sujeción a las nuevas retribuciones fijadas respecto al personal de Administración local en virtud de lo preceptuado en el Decreto-ley de 16 de diciembre de 1969 y Decreto del día 19 siguiente. (Sentencia de 12 de junio de 1974, Ar. 2.713).

\section{VIUdEDAD PRODUCIDA POR FUNCIONARIO JUBILADO EN EL AÑo 1954}

ConsIDERANDO: Que tratándose de pensión de viudedad por fallecimiento en 1969 de funcionario municipal jubilado en 1954 y ser el hecho de la muerte el determinante del nacimiento del derecho a percibirla, como viene declarando la Sala en sentencias, entre otras, las de 23 de mayo y 13 de junio de 1973, la legislación aplicable para señalar el porcentaje sobre el que, en relación con el haber regulador, haya de ser calculada dicha pensión de viudedad es la contenida en el Estatuto de la Mutualidad Nacional de Previsión de la Administración Local, fecha 12 de agosto de 1960, concretamente en su artículo 46, el cual preceptúa que, en caso de pensión ordinaria como la actual, será el del 45 por 100 del haber regulador, con lo que, en resumen y dada la inaplicabilidad del artículo 47 del Estatuto de Clases Pasivas de 1926, argumentado en la demanda para fundamentar el porcentaje del 25, procede desestimar el recurso y, en consecuencia, mantener la impugnada resolución que dictó el Ministerio de la Gobernación en 23 de diciembre de 1970, fijando el porcentaje del 45. (Sentencia de 5 de junio de 1974, Ar. 2.593).

\section{HACIENDAS LOCALES}

\section{ARbitrio POR EDIFICACIÓN DEFICIENTE}

Que el arbitrio sobre edificación deficiente es de los definidos como de naturaleza no fiscal en el artículo $434,1, c$ ), y 473 de la Ley de Régimen local y artículo 46 del Reglamento de Haciendas locales, encontrándose dentro de la Ley del Suelo en el artículo 162, 1, de ésta, de 
cuyos preceptos resulta que la efectividad del mismo está en función de la causa final que lo justifica, la cual no es otra que ejercer una coacción o un estímulo para que los solares sin edificar o insuficientemente edificados lleguen a estarlo según les corresponda, razón de ser de fomento de la edificación, que es la base de su existencia, y que la diferencia claramente del tributo propiamente fiscal cuya razón de ser se justifica por la necesidad de obtener recursos para los entes públicos, siendo en este caso la realización del hecho imponible lo que determina el nacimiento de la obligación tributaria.

Que el período de la exacción discutida es el año 1966, y concurren aquí los siguientes hechos: el 27 de abril de 1965 son ingresadas las tasas por licencia de derribo de la edificación de una planta existente en el solar: el 18 de abril de 1966 concluyen las operaciones de aquel derribo según certifica el Arquitecto director de la obra, y el 21 de octubre de 1966 se abonan las tasas de licencia de obras para las que se van a realizar en la finca, cuyas obras dan comienzo el 2 de noviembre del mismo año, según certifica también el Arquitecto director de las mismas, circunstancias todas ellas que ponen de manifiesto cómo no sólo falta cualquier indicio de negligencia en las sociedades propietarias respecto a su actividad dirigida a construir sobre el solar objeto de la exacción, sino que, por el contrario, se prestó la atención y fue desarrollada una actividad adecuada a conseguir los necesarios requisitos administrativos y medios indispensables para que esa construcción pudiera tener efectividad, careciendo de fundamento este tributo dirigido a estimular una actuación que se produjo sin necesidad de apremio, criterio el expuesto que ha sido mantenido por la Sala 3. ${ }^{\mathrm{a}}$ del Tribunal Supremo en sentencia de 22 de abril de 1970. (Sentencia de 14 de junio de 1974, Ar. 2.835).

\section{ARbitrio de plusvalfa: NOtificación obligada al ENAJENANTE}

Considerando: Que en cuanto a la causa de nulidad que se aprecia por el Tribunal a quo, al no haberse notificado la liquidación por incremento del valor de los terrenos al enajenante, dicha doctrina es de forzosa aplicación, ya que el enajenante es el sujeto pasivo del arbitrio sobre el que normalmente recae, si bien a efectos del pago se impone la obligación de satisfacerle al adquirente, quien podrá repercutirlo sobre aquél, salvo pacto en contrario, normas de rango legal establecidas por el artículo 517 de la que regula el Régimen local de 24 de junio de 1955, por lo que el carácter de interesado directo y principal del enajenante en el arbitrio en cuestión impide por principio de justicia que se tramite el expediente sin su conocimiento, y tan sólo con el del adquirente, pues, aunque éste ocupa el puesto aparente de interesado, salvo pacto en contra, será el enajenante el que soporte el gravamen, y a ese efecto, como se ha visto, se concede al adquirente acción de reembolso contra el obligado, razones a las que todavía hay que añadir, que 
es el enajenante, como titular de la finca transmitida, quien está en mejores condiciones de comprobar la exactitud de los datos sobre los que haya operado la liquidación del arbitrio, y sin duda ante estas consideraciones el Reglamento de Haciendas locales de 4 de agosto de 1952, al regular este arbitrio y desarrollar los preceptos del texto primitivo de la Ley de Régimen local, impone expresamente el deber de notificar las liquidaciones a las personas interesadas a que se refieren los artículos 515 y 516, que en la actualidad se corresponden con los artículos 517 y 518 de la Ley de Régimen local, y por tanto en el caso de transmisiones comprendidas en el apartado c) del artículo 517, como ocurre en el caso presente, la notificación habrá de ser hecha al enajenante por ser sobre quien el arbitrio recae y también conforme al actual artículo 518, 1, b), habrá de notificarse al adquirente por imponérsele al mismo la obligación de pago, aunque sólo sea a efectos de su ulterior repercusión, doctrina ya reiterada por esta Sala en sus sentencias, entre otras, de 1 de marzo de 1967, 4 de octubre de 1971 y 28 de enero de 1974, por lo que, como en las mismas se establece, es forzoso anular el expediente a partir del momento en que las notificaciones deben ser hechas tal y como acertadamente se ordena en la sentencia apelada. (Sentencia de 26 de mayo de 1974, Ar. 2.505).

\section{ARbitrio de plusvalfa: terRenos suJetos al mismo}

De conformidad a la doctrina sentada por la Sala 3.a del Tribunal Supremo, el artículo 510 de la Ley de Régimen local establece el principio general en el susodicho arbitrio de la sujeción a él de las transmisiones de todos los terrenos situados en el término municipal, con la única exclusión de los afectos a las explotaciones que el propio precepto enumera, entre las que se hallan las agrícolas, siempre que estos terrenos, a su vez, no tengan la consideración legal de solares: causas de no sujeción cuya concurrencia ha de ser probada por los interesados, a quienes corresponde esa carga, conforme a los principios generales que la rigen y se contienen en materia fiscal en los artículos 114 y 8 de la Ley General Tributaria, y las que precisamente han de existir o producirse en el momento en que la transmisión tenga lugar, conforme a la constante jurisprudencia del Tribunal Supremo manifestada, entre otras, en las sentencias de su Sala $3 .^{a}$ de 14 de mayo y 9 de junio de 1965, 29 de marzo de 1966, 21 de marzo de 1967 y las numerosas que se citan en la más reciente de 9 de marzo de 1970. (Sentencia de 28 de mayo de 1974, Ar. 2.563).

\section{ARbitrí́ de plusvalia: terrenos agrfColas}

Considerando: Que en cuanto a los temas de fondo se ha alegado por la recurrente, en primer lugar, que la finca de que se trata está excluida del ámbito de aplicación del arbitrio de plusvalía a tenor de lo dispuesto en el artículo 510 de la Ley de Régimen local, por estar 
afecta a una explotación agrícola y no tener la consideración legal de solar; aduciendo, en abono de su tesis del destino agrícola del terreno, que el mismo fue segregado de una finca mayor conocida por «Camp Llarch" dedicado al cultivo de regadío desde tiempo inmemorial y que conservaba este destino en el momento de su transmisión, que es el que tiene trascendencia a efectos del arbitrio, circunstancia que estimaba acreditada por la propia descripción de la finca en la escritura de -adquisición, por figurar incluida la misma en el Catastro de rústica; tributando a la Hacienda pública en tal concepto, así como por el arbitrio municipal sobre la riqueza rústica, Seguridad Social Agraria, impuesto para la defensa contra las plagas del campo, Cámara Oficial Sindical Agraria y Hermandad Sindical de Labradores y Ganaderos; pero a esta alegación debe oponerse que estas circunstancias por sí solas no bastan para probar el destino agrícola de una finca, pues la calificación rústica de un suelo a los efectos de la Contribución Territorial, y a consecuencia de ella los aludidos impuestos y exacciones, no determina necesariamente su exclusión del arbitrio sobre el incremento del valor de los terrenos, pues, pese a esta calificación, pueden no estar destinados a un aprovechamiento agrícola - sentencia del Tribunal Supremo de 21 de junio de 1963-. (Sentencia de 10 de junio de 1974, Ar. 2.762).

\section{ARbitrio de Plusvalfa: tasa de EQUivalencia: TERRENOS DE CONGREgación RELIGIOSA DEDICADA A LA ENSEÑANZA RETRIBUIDA}

CONSIDERANDo: Que al ser ya obligado el examen de la cuestión de fondo planteada por la Congregación religiosa recurrente, en virtud de lo dispuesto en el artículo 100,7, de la Ley, conviente poner de relieve que la liquidación por importe de 1.178.927,65 pesetas vino a sustituir a otra anterior, que ascendía a 2.393.439,63 pesetas, después de haber realizado en favor del Ayuntamiento una rectificación de la base y de haber aplicado en beneficio de la Congregación la exención del 52,844 por 100, a tenor del artículo 520, 1, 1, de la Ley de Régimen local, por la parte de terreno correspondiente a la capilla y a la casa religiosa; exención que no es posible conceder en su totalidad porque no se ha acreditado que se trate de un centro benéfico-docente, con lo que la actividad de enseñanza, aunque sea una obra de apostolado, se ejerce mediante retribución y cae de lleno en el inciso final del precepto de la Ley de Régimen local que se deja citado; sin que esta conclusión se desvirtúe por el apartado $4 .^{\circ}$ del artículo XX del Concordato, que está proclamando la sujeción de todos los demás bienes e ingresos en paridad de condiciones con las demás instituciones o personas y que no permite aplicar a los bienes una argumentación, a contrario, que se deduce respecto de los ingresos, cuando a los bienes se refiere privativamente el apartado $1 .^{\circ} \mathrm{y}$ a los ingresos el apartado $3 .^{\circ}, \mathrm{y}$ en cuanto a la proporcionalidad de la distribución entre la parte exenta y la no exenta no se ha combatido con otras pruebas el parecer del Arquitecto municipal, que asignó el 52,844 por 100 a la parte exenta y el 47,156 
por 100 a la no exenta, por lo que carece esta Sala de elementos de juicio suficientes para disponer una rectificación de la liquidación girada y debe concluir en sentido semejante a como se pronunció la sentencia de 15 de mayo de 1972. (Sentencia de 12 de junio de 1974, Aranzadi 2.830).

\section{CoNTRIBUCIOSES ESPECIALES: POR AUMENTO DE VALOR}

Considerando: Que, en términos generales, sería aventurado pro clamar que los terrenos de viales o de parques y jardines no experimentan, por no ser edificables, aumento de valor como consecuencia de las obras de referencia, ya que, siguiendo las normas de la Ley del Suelo, es preciso distinguir.entre aquellos terrenos incluidos en el apartado b) del artículo 90, de aquellos otros incluidos en el artículo 97, que pueden ser compensados al entrar en la solidaridad de beneficios y cargas que es de esencia en el «sistema de compensación» de la sección cuarta del capítulo II del título III de la Ley del Suelo, pues en este caso excepcional sí que se produce el incremento de valor como consecuencia de las obras.

CoNSIDERANDO: Que en el expediente administrativo existe abundante prueba de que la finca objeto de este recurso está clasificada en el Plan comarcal como parque urbano, sin que le resulte aplicable el sistema de compensación, por cuyos motivos es procedente compartir el criterio de la sentencia recurrida en orden a cuales son los propietarios de terrenos beneficiados por las obras, entre los que no se encuentran, evidentemente, aquellos a quienes el planeamiento relega a la situación de viales, parques y jardines y zonas verdes de uso público, ya que respectos de ellos no existe incremento de valor ni, por ende, cabe gravar con las contribuciones especiales por razón de obras. (Sentencia de 26 de mayo de 1974, Ar. 2.509).

\section{CONTRIBUCIONES ESPECIALES: POR ALUMBRADO}

Considerando: Que en definitiva la alegaciones de la Corporación municipal pretenden hacer prevalecer su criterio de predominio del interés particular en las obras de alumbrado público de que se trata, por lo que solicita se declare ajustado a Derecho el acuerdo municipal de 5 de octubre de 1972, que asignó a las fincas beneficiadas el 80 por 100 del importe de las obras, mientras que la comunidad propietaria de tales fincas pide en su demanda que tal participación se limite al 5 por 100 de dicho importe, por estimar pre lominante el interés general.

Considerando: Que siendo un hecho admitido por las partes el emplazamiento de las fincas precisamente en el tramo de intersección de la calle del General Elorza con la autopista de Oviedo a Gijón, resulta 
evidente el interés público predominante en el alumbrado proyectado por el Ayuntamiento, por lo que no cabe aceptar la pretensión municipal de asignar a los particulares afectados el 80 por 100 del coste de las obras de dicho servicio, proporción que representa precisamente el máximo permitido por la Ley de Régimen local en su artículo 470, 1, participación que con acierto han denegado tanto el Tribunal Económico-Administrativo Provincial como el Tribunal a quo, pues es incompatible la existencia de un predominante interés general con la máxima atribución posible de su importe a los propietarios de las fincas beneficiadas, pero como por otra parte el artículo 469 incluye en su apartado g) entre los servicios que producen un beneficio especial el establecimiento de alumbrado y mejora del mismo, también debe participar la propiedad de las fincas afectadas en el discutido coste, y atendidas las circunstancias concurrentes, entre ellas la muy importante de que la instalación se verifica en una autopista que comunica la capital asturiana con la ciudad marítima de Gijón, parece equitativo fijar dicha participación en el 35 por 100, siguiendo criterios ya anteriormente marcados por esta Sala en casos de indudable analogía, ya que el interés general de la iluminación de una autopista que parte de una importante capital determina por sí esa prevalencia de interés general, atendida la intensidad del tráfico viario en la actualidad. (Sentencia de 14 de junio de 1974, Ar. 2.834).

\section{CONTRIBUCIONES ESPECIALES: PAVIMENTACiÓN, ALCANTARILLAdO $Y$ OTRAS}

Considerando: Que no discutido el hecho de que a Mercados y Edificios Públicos, S. A.», es concesionaria del Mercado de Maravillas, sujeto a reversión en favor del Ayuntamiento de Madrid, sino tan sólo que sea aplicable la exención de contribuciones especiales, por razón de las obras que afectaron a dicho Mercado, habrá que tener en cuenta la prioridad normativa establecida en el artículo $10^{\circ}$ de la Ley Especial para el Municipio de Madrid, de 11 de julio de 1963, precepto según el cual regirá en primer lugar la propia Ley Especial y después, en cuanto a ella no se opongan, la Ley de Régimen local y sus disposiciones reglamentarias, por lo que el artículo 90 de la Ley de Madrid, que encabeza la sección relativa a Contribuciones Especiales, es el precepto clave para resolver la controversia surgida, pues la preferencia sobre otros preceptos o está proclamada en el artículo $10^{\circ}$ antes citado, si se refieren al Régimen local común, o surge del mismo principio de jerarquía de las normas, si se trata de preceptos reglamentarios específicos para la capital del Reino, y puesto que el párrafo 2. del artículo 90 de la Ley Especial se refiere al artículo 469 de la Ley de Régimen local, que enumera los supuestos de imposición de contribuciones especiales, distintos de los en que se produzcan determinados aumentos de valor, para remitirse inmediatamente, al señalar las exenciones o bonificaciones, al artículo 468 de la Ley común y no al 472, a pesar de que el 
primero está en la subsección anterior al artículo 469 y el segundo en la misma subsección, no cabe discutir ya cuál sea el precepto de la Ley de Régimen local aplicable por reenvío de la Ley Especial, pues claramente se indica en la última que es el artículo 468 de la primera, y toda alteración posterior de este reenvío exigirá una norma con categoría de ley formal, que no se ha dictado después del 11 de julio de 1963, por todo lo cual y por los razonamientos de la sentencia apelada, que se dejan aceptados, es procedente su confirmación, sin declaración de costas en esta segunda instancia, de acuerdo con el artículo 131 de la Ley Jurisdiccional. (Sentencia de 5 de julio de 1974, Ar. 3.196).

\section{CONTRIBUCIONES ESPECIALES: IMPUGNACIÓN}

Considerando: Que el artículo 36 del Reglamento de Haciendas lo cales de 4 de agosto de 1952, referente a esta clase de contribuciones, dice que cuando la reclamación versare sobre el incremento de valor, una vez admitida se suspenderá toda tramitación hasta que terminen las obras o instalaciones o comiencen a prestarse los servicios que mo tiven la construcción, y el Ayuntamiento tase nuevamente las fincas con intervención del propietario, es decir, que relega la determinación de la cuantía de la base liquidable (que será el incremento resultante), tasación pericial contradictoria ante el Tribunal EconómicoAdministrativo Provincial.

Considerando: Que el antedicho precepto, aplicado y comentado con claridad por la sentencia de esta Sala de 27 de junio de 1973, afecta a aquellos casos en que lo que se discute es la cuantía del «incremento resultante como consecuencia de las obras», mas por evidentes razones de economía no se debe aplicar a aquellos otros casos en que la interpretación de la normativa que rige la actividad urbanística conduzca a la apreciación de que, en determinada finca, no es posible que el incremento se produzca, y la liquidación sería improcedente por falta de base liquidable o, mejor, por no ser ésta positiva. (Sentencia de 16 de mayo de 1974, Ar. 2.509).

\section{LICENCIA FISCAL DEL IMPUESTO INDUSTRIAL: CENTRAL H IDROELÉCTRICA}

Considerando: Que según el artículo 5..$^{\circ}$ de la Ley de 23 julio de 1966, se atribuirán directamente "a los Municipios en cuyo término radiquen los bienes o se desarrollen las actividades sujetas a gravamen, el 90 por 100 de las cuotas de Contribución Territorial Urbana» y el 90 por 100 de la cuota de licencia fiscal del impuesto industrial; precepto legal que tiene que interpretarse, necesariamente, en el sentido de que mientras para la determinación del Ayuntamiento perceptor de la participación en la Contribución Territorial Urbana ha de estarse al elementos físico del lugar en que se encuentren los bienes gravados, 
para la concreción del Ayuntamiento acreedor a la participación en la cuota de licencia fiscal del impuesto industrial se ha de prescindir de ese dato físico para estar únicamente al del lugar donde se desarrollen las actividades sujetas al gravamen -constitutivas, en suma, de su «hecho imponiblew-, abstracción hecha del lugar en que se encuentren los bienes.

Considerando: Que la solución de este problema de localización del hecho imponible en el supuesto de litis viene dada, sin duda, por el artículo 7.0 del Texto Refundido de la Ley sobre Actividades y Beneficios Comerciales e Industriales de 29 de diciembre de 1966, a tenor del cual "las actividades constitutitivas del hecho imponible» «se especificarán en las tarifas del impueston, donde entre otros principios prevalentes se delimitará el contenido de dichas actividades gravadas, de acuerdo con las características de los sectores económicos, «tipificándolas mediante elementos fijos»; es visto que en el presente caso el atipon, el símbolo representativo de la mencionada actividad de fabricación $-\mathrm{y}$ basta la lectura del expresado epígrafe para comprobarlo-, lo constituyen tan sólo los elementos fijos a que el mismo se refiere; es decir, los ageneradores instalados», en su doble vertiente, de elementos cuantificadores de la deuda tributaria y de símbolos representativos «localizadores» en suma por imperio de la ley, de las actividades constitutivas del hecho imponible.

Considerando: Que a idéntica conclusión se llega si se tiene en cuenta el propósito que el legislador deja patente en la exposición de mo tivos de la Ley de 23 de julio de 1966, al exponer: que una de sus finalidades fundamentales es la de localizar hasta donde sea posible los ingresos municipales, asignándolos al Ayuntamiento adonde radique la base imponible», y ello no sólo por la perfecta adecuación de estas palabras a la tarifa de la licencia fiscal -aunque deba reconocerse que la base impositiva uinserta en ella» no aparece de forma inmediata como elemento operativo para fijar la cuantía de la cuota-, sino por ser indudable que el verdadero sentido del párrafo transcrito no es el de privar al «hecho imponible» de su papel estelar en el proceso de asignación de cuotas, antes al contrario: simplemente servirse de la base imponible para alocalizarlo» en un primer paso de ese gran afán, que iba a realizarse meses después, en el artículo $70^{\circ}$ del Texto Refundido de 29 de diciembre de 1966, con la decisiva contundencia que ofrecen, como dicho queda, esos símbolos representativos del hecho imponible, que son, en definitiva, los «elementos fijos» especificados en la tarifa.

Considerando: Que si por el peso de estas razones se impone, en efecto, concluir que el whecho imponible» que origina el devengo de la deuda tributaria a que se refiere el apartado $a$ ) del epígrafe 8.121 de las tarifas del impuesto industrial, es la "producción de energía eléctrica» -producción de energía que se localiza, repítese, a través de esos ele- 
mentos fijos, que son los ageneradores instalados»-, claro es que, en consecuencia, la participación y los recargos en las cuotas abonadas por la Compañía Sevillana de Electricidad por la central del pantano de «El Tranco» que en este pleito se discuten, exclusivamente corresponden al Ayuntamiento de Villanueva del Arzobispo, en cuyo término municipal está situada la central productora, donde se encuentran instalados los generadores, como certeramente ha dictaminado la Dirección General de lo Contencioso y resuelto el Ministerio de Hacienda en la resolución impugnada. (Sentencia de 10 de mayo de 1974, Ar. 2.361).

\section{JURISDICCION CONTENCIOSO-ADMINISTRATIVA}

\section{Dictamen de Letrado}

Resulta indudable que se ha cumplido en este procedimiento la expresada formalidad, exigida por el citado artículo de la Ley de Régimen local y matizada por el 338 del Reglamento de Organización, Funcionamiento y Régimen jurídico de las Corporaciones locales de 17 de mayo de 1952 - con tanta más razón cuanto que en el expediente administrativo ya existen dictámenes de Letrado que permiten dar por supuesta la conclusión a que habría de llegarse a efectos de la interposición de los recursos que se contemplan-, sin necesidad de que los expresados dictámenes consten originales o literalmente testimoniados si ha de seguirse el criterio informador de la propia Ley reguladora de la jurisdicción, palmariamente expuesto en su preámbulo y que consiste en evitar interpretaciones formalistas. (Sentencia de 10 de mayo de 1974, Ar. 2.361).

\section{Legitimación activa DE MUNICIPIO AFECTADo POR UNA AUTOPISTA}

Considerando: Que imputándose por el Abogado del Estado falta de legitimación activa al Ayuntamiento recurrente, deben examinarse con carácter previo las causas de inadmisibilidad de estos recursos que han sido opuestas por el representante de la Administración por el orden en que han sido formuladas, indicándose, en primer lugar, la falta de interés directo en la Corporación demandante, interés que no cabe negarle al Ayuntamiento de Zarauz no sólo por haber sido parte en el expediente informativo previo a la aprobación definitiva del pro yecto y haberle sido reconocida por la Administración el interés directo en todas las escalas administrativas, por lo que no puede ser negado posteriormente al acudir a esta vía jurisdiccional, pero además, por existir la poderosa razón legal de afectar el trazado de la autopista, en su paso por la jurisdicción de Zarauz, cuyos tramos son los que se discuten, a los intereses municipales del citado Ayuntamiento sobre los que repercute de una manera directa, puesto que entendiéndose por 
término municipal el territorio a que extiende su jurisdicción cada Ayuntamiento, y siendo notorio que el proyecto de la nueva autopista en parte pasa por el territorio de Zarauz, no cabe negar o desconocer legitimación activa a la Corporación recurrente para impugnar las resoluciones recurridas, dada la competencia asignada a los Municipios y las atribuciones que la Ley de Régimen local confiere a los Ayuntamientos, defensa de los intereses locales que el propio Reglamento de Carreteras reconoce existir; en el artículo 13, en todo proyecto de carretera, como necesaria consecuencia física de implantarse una nueva vía de comunicación terrestre y estar integrado todo el territorio nacional en términos municipales. (Sentencia de 10 de junio de 1974, Aranzadi 2.767).

\section{MUNICIPIOS}

\section{INCORPORACIÓN POR NECESIDAD O CONVENIENCIA ADMINISTRATIVA}

Aunque emitió informe contrario a la incorporación el Consejo de Estado, la sentencia declara ajustado a derecho el acto administrativo que dispuso la incorporación. Se dice en la sentencia:

Considerando: Que la resolución del Consejo de Ministros, aprobando por Decreto de 17 de abril de 1960 la incorporación que en este recurso se combate, se apoya en los motivos de conveniencia o necesidad que exigen el artículo 14 en relación con el apartado $c$ ) del artículo 13 de la Ley de Régimen local y en el 82 del Reglamento de Población y Demarcación Territorial de las Entidades locales, artículos $4 .^{\circ}$, número 8,14 y 24 , y, por consiguiente, apreciando los hechos determinantes con arreglo a la valoración de los elementos probatorios y por estimar se dan las condiciones exigidas legalmente, vino en resolver con arreglo a derecho respecto a la conveniencia de constituir a Ripoll en capitalidad administrativa, como lo es geográfica y económica, acordando la incorporación que constituye el acto administrativo recurrido, y que, por consiguiente, es de confirmar en el aspecto del recurso, posición en 14 de octubre de 1970, pues la cuestión planteada ha sido resuelta con criterio vitalizado y dentro de la aplicación normativa con arreglo al ordenamiento jurídico. (Sentencia de 29 de mayo de 1974, Aranzadi 2.542).

\section{POLICIA MUNICIPAL}

\section{LICENCIA: HORNOS DE PAN: COMPETENCIA MUNICIPAL}

CoNSIDERANDo: Que en orden a la validez del expediente, necesario es distinguir entre la autorización estatal de industria y municipal, pues mientras aquélla dimana de la Ley de Ordenación y Defensa de 
la industria nacional, sólo modificada en su básica estructura por el Decreto-ley de 14 de febrero de 1963, en cuanto a la industria harinopanadera se refiere, la municipal tiende a garantizar la convivencia humana dentro del ámbito urbano, cuya custodia y ordenación le está encomendado; es necesario, pues, que existan las dos licencias, determinadas cada una por su peculiar normativa. (Sentencia de 13 de mayo de 1974, Ar. 2.496).

\section{MULTAS: PRESCRIPCIÓN}

Del examen de las respectivas denuncias consta que desde que fueron éstas formuladas hasta que figuran los respectivos Decretos sancionadores no había aún transcurrido el plazo de prescripción establecido en el artículo 114 de la Ley de Régimen local de 24 de junio de 1955, que remite al de dos meses prevenidos para las faltas en el artículo 113 del Código penal; pero, en cambio, resulta que desde la fecha de tales Decretos hasta que en realidad se notificaron a la compañía sancionada había transcurrido con exceso no solamente el plazo legal para ser notificados los actos administrativos resolutorios, que es de diez días, conforme a los artículos 312 del Reglamento de Organización, Funcionamiento y Régimen jurídico de las Corporaciones locales de 17 de mayo de 1952 y artículo 79 de la Ley de Procedimiento administrativo de 17 de julio de 1958, sino también el indicado de dos meses que para la prescripción de las faltas administrativas se prescribe en los antes mencionados preceptos legales, puesto que transcurrió un lapso de tiempo superior al año, en el que hubo una total paralización del referido procedimiento sancionador; y como igualmente se comprende por aplicación interpretativa de las normas con que en dicho Código penal se regula el cómputo de plazos, sus interrupciones y reanudación a tales efectos prescriptivos permite sostener que una vez transcurrido el plazo de diez días señalado legalmente para practicar la notificación sin efectuarla, el plazo de prescripción comienza a correr de nuevo, con lo que en este supuesto aparece una total y absoluta paralización de los mentados expedientes sancionadores de un lapso de tiempo superior al año en procedimientos administrativos aún no ultimados, al ser posible legalmente una nueva instancia, y cuando en todo caso, aunque fuese una sanción impuesta dentro del plazo legal, siempre sería ante la expresada paralización superior al año, aplicable la prescripción prevista en el artículo 115 del vigente Código penal, con respecto a las penas leves, atendida la equiparación prescriptiva dispuesta por la Ley de Régimen local en el mencionado artículo 114 de la misma.

Considerando: Que no es obstáculo a la conclusión anteriormente expresada del argumento opuesto en la resolución administrativa contra la que en esta vía jurisdiccional se recurre, en base a que las multas de que se trata constituyeron exacción prevista en el artículo 434, 
apartado e), de la Ley de Régimen local y ser, por tanto, su plazo de prescripción el de cinco años, que para ellas se establece en el artículo 796, apartado $b$ ), del mismo Cuerpo legal; pues ha de tenerse en cuenta que la multa no adquiere carácter de exacción sino después de que impuesta y comunicada al sancionado adquiera firmeza, y en este caso la prescripción se ha producido por mera paralización del procedimiento sancionador y no en el económico-administrativo o su equivalente de ejecución, de lo que se infiere que la prescripción de cinco años podrá afectar a la multa en su calidad de exacción, pero nunca al concepto de prescripción de infracciones, que tiene su normativa específica en el artículo 114 de la Ley local ya citada, y como en el supuesto contemplado en este recurso el plazo de prescripción había ya transcurrido con exceso y producido sus efectos con anterioridad a la aludida firmeza de las sanciones impuestas, es obvio que resulta por completo irrelevante el argumento opuesto para la aplicación del referido plazo prescriptivo. (Sentencia de 28 de mayo de 1974, Ar. 3.105).

\section{Piedras que amenazan caer sobre un poblado}

Compete a la autoridad municipal adoptar las medidas que estime oportunas, exigiendo del propietario del terreno que las lleve a cabo con la premura que el caso exija, y realizándolas la propia Administración a costa del obligado si éste no las ejecuta en su tiempo. (Sentencia de 4 de mayo de 1974, Ar. 3.099).

\section{PROCEDIMIENTO ADMINISTRATIVO}

\section{Dictamen de Letrado previo al EJERcicio de acciones POR LAS CORPORACIONES LOCALES}

El dictamen de Letrado, definido en el artículo 370 de la Ley de Régimen local, como previo al acuerdo de ejercicio de acciones por las Corporaciones locales, es requisito esencial cuya inexistencia determina inadmisibilidad del recurso contencioso actuable incluso de oficio por afectar al orden público rituario, con imperativa subsunción, cuando se acoge en la sentencia, en el artículo 81, número 1, de la Ley Jurisdiccional y fundamento en los supuestos establecidos en el siguiente, 82, bien sea el previsto en su apartado $b$ ), por cuanto se trata de requisito condicionante de la validez del acuerdo con la implicada carencia en su caso de «legitimación activa ad processum», o ya resulte incluido en el apartado $f$ ) del mismo precepto, toda vez que el defecto cuestionado motiva presentación del escrito inicial en forma defectuosa a tenor del artículo 57, número 2, apartado d), de la Ley referenciada, con la observación de que la exigencia del susodicho dictamen tanto concierne 
al ejercicio de acciones estrictamente judiciales, en cuyo concepto corresponde agrupar la determinante de esta primera instancia jurisdiccional, como a las de índole administrativa, según resulta de la genérica denominación de acciones que a este efecto utiliza el artículo 338, número 1, del Reglamento de Organización, Funcionamiento y Régimen jurídico de las Corporaciones locales de 17 de mayo de 1952, en relación con los 121, apartado $j$ ), y 122, apartado $i$ ), de la Ley de Régimen local y 122, número 4, y 123, número 12, del Reglamento referido, interpretación que no aplica extensivamente el requerimiento legal de aquel dictamen, sino que tan sólo concreta y especifica los supuestos contenidos en la dicción normativa, que no por abstracta puede alterar su estricto alcance en cuanto implica restricción formal para la libre defensa de los derechos, en debida coordinación con las garantías de imparcialidad, objetividad y asistencia técnica también necesaria para proteger los intereses del Municipio, que en este aspecto son distintos de los inherentes a su defensa procesal por Letrado conforme al artículo 35, número 1, de la Ley reguladora de la jurisdicción. Y en el presente caso, ni en la vía administrativa, ni tampoco contenciosa, existió dictamen de Letrado en ejercicio, insustituible por el del Secretario del Ayuntamiento, aunque también hubiera poseído la condición de Abo gado. (Sentencia de 14 de mayo de 1974, Ar. 2.500).

\section{NOTIFICACIÓN AL PRIMER FIRMANTE DE UN ESCRITO FIRMADO POR VARIOS}

ConsIDERANDo: Que los vicios de tramitación del expediente administrativo alegados por la parte actora se pretenden derivar de defecto formal de las notificiaciones efectuadas por haber sido realizadas al primero de los firmantes del recurso de reposición, cuando estima se debió practicar notificaciones individuales a cada uno de los interesados, y en la omisión de trámite de audiencia; el primero carece de base, ya que comparecidos los interesados, previamente citados, mediante escrito dirigido a la autoridad municipal, suscrito conjuntamente por todos ellos con aportación de informe técnico y designación de arquitecto que intervino en las actuaciones, la notificación efectuada al interesado que suscribió el escrito en primer término se ajusta a lo prevenido en el artículo 25 de la Ley de Procedimiento administrativo, aplicable a estos efectos, e igualmente debe ser rechazada la segunda alegación por ser la tramitación adecuada a los expedientes de la naturaleza del discutido, la que señala el artículo 170 de la citada Ley del Suelo, que sólo exige tengan el carácter de contradictorios, lo que ha sido concretamente cumplido. (Sentencia de 20 de mayo de 1974, Aranzadi 2.517). 


\section{RECURSO DE REPOSICIÓN Y NO MERA DENUNCIA DE NOTIFICACIÓN DEFECTUOSA}

Por tanto, en dicho escrito no se limita a ejercer el derecho que le otorga el artículo 79 , número 4 , de la Ley de Procedimiento administrativo para que se rectifique la deficiencia en la notificación del acuerdo, sino que hace peticiones y razonamientos sobre la improcedencia de la decisión adoptada, peticiones que son incompatibles entre sí, puesto que el acto administrativo sólo puede ser combatido desde el momento en que ha sido notificado a los interesados, bien por haberse cumplido los requisitos legales o porque se den los interesados por notificados; por tanto, ante tales peticiones contradictorias entre sí; el Ayuntamiento se encontró con la obligación de calificar jurídicamente el escrito presentado, lo que hizo correctamente al contener el mismo todos los elementos precisos para ser calificado de recurso de reposición. (Sentencia de 28 de mayo de 1974, Ar. 2.538).

\section{SANIDAD}

1. SERVICIO DE DESINFECCIÓN Y DESINSECTACIÓN: COMPETENCIA MUNICIPAL

Considerando: Que la prestación de los servicios de desinfección y desinsectación, como medios de defensa de la salubridad e higiene públicas y preservación de epidemias, viene atribuida a los Municipios por preceptos de rango legal, tales como el artículo 102, en su apartado $h$ ), y 101, apartado $c$ ), de la Ley de Régimen local.

ConsIDERANDo: Que los preceptos impugnados en este proceso, contenidos en el apartado $b$ ) del artículo $15 \mathrm{y}$ en la disposición transito ria 1.a de la Orden del Ministerio de la Gobernación de 24 de julio de 1962, publicada en el Boletín Oficial del Estado de 24 de agosto del mismo año, atentan a la integridad de la competencia municipal, infringiendo manifiestamente la legalidad de rango superior mencionada en los considerandos precedentes cuando, respectivamente, prohíben a los Laboratorios municipales actuar como empresas de desinsectación re tribuidas por los interesados y limitan sus autorizadas actividades de desinsectación remunerada hasta un año después de que en la Provincia respectiva se constituya una empresa privada autorizada para la realización de dicho servicio. En su virtud procede declarar nulas de pleno derecho, tanto el artículo 15, apartado $b$ ), como la primera disposición transitoria de la mencionada Orden ministerial, a tenor de lo dispuesto en el número 2 del artículo 47 de la Ley de Procedimiento administrativo y 28 en relación con el 26 de la Ley de Régimen jurídico, por 
lo que es procedente estimar este recurso contencioso-administrativo interpuesto contra tales disposiciones generales por el Ayuntamiento de Madrid. (Sentencia de 13 de mayo de 1974, Ar. 2.491).

\section{SERVICIOS FÚNEBRES: COMPETENCIA}

Considerando: Que el Reglamento de Policía Mortuoria de 22 de diciembre de 1960 no altera los cometidos que a los Ayuntamientos atribuyen la Ley de Régimen local y disposiciones complementarias, por cuanto el artículo 47 proclama la competencia de autoridad municipal para otorgar las autorizaciones precisas para el establecimiento de toda empresa fúnebre (al margen de la exigencia o presupuesto previo del informe favorable de la Jefatura Provincial de Sanidad o de la aprobación de tarifas por el Gobierno Civil, inspección, etc., nacidas de una competencia compartida por el Estado en virtud o por razón de la policía sanitaria), y que el artículo 46 -dejando a salvo las opciones que en cuanto a la forma de prestación atribuyen a los Ayuntamientos los artículos 157 y 158 de la Ley de Régimen local- del Reglamento, con criterio orientativo y en razón de los medios disponibles y demás circunstancias concurrentes en cada localidad (no otra cosa puede significar «de ser posible»), preceptúa que en las poblaciones de más de 10.000 habitantes existirá, por lo menos, una empresa funeraria que cuente y disponga de los elementos y medios que en el propio precepto se señalan, mas ello no quiere decir que la autoridad municipal, al reglamentar el servicio, no puede limitar el número de empresas de tal clase en función de las características de la población, rentabilidad de la actividad, eficiencia del servicio, etc., municipalizar tal actividad, etc., dado que, atendiendo a la naturaleza del mismo, la prestación puede efectuarse a través del régimen de licencia o autorización administrativa, de concesión o de gestión directa, y la limitación que a la actuación de los particulares suponga el sistema de licencia previa y limitada en cuanto al número no encuentra hecho alguno, por ser campo atribuido ex lege a la competencia municipal, sin existencia de precepto legal que prohíba la limitación de autorizaciones y más bien amparado en las normas permisivas contenidas en los artículos 13 , número 2,30 y 33 y concordantes del Reglamento de Servicios de las Corporaciones locales. (Sentencia de 20 de mayo de 1974, Ar. 2.502).

\section{SERVICIOS}

\section{MƯNICIPALIZACIÓN: REVISIÓN DE TARIFAS: APROBACIÓN}

El problema de la competencia objetiva del Departamento ministerial de Gobernación para la aprobación de la modificación de tarifas, en este caso çonforme a la normativa aplicable con anterioridad a la 
vigencia de la Ley de 23 de julio de 1966, viene afirmativamente resuelto por la sentencia del Tribunal Supremo de 9 de abril de 1968 al resolver recurso interpuesto por la compañía recurrente contra las resoluciones de dicho Ministerio de 28 de septiembre y 31 de mayo de 1963 -la primera desestimatoria del de reposición entablado contra la segunda-, que aprobaron la revisión de las tarifas, trienio 1961-1963, en el que, con carácter preferente en atención a su naturaleza, se planteó de frente la cuestión de referencia; por tanto, reiterando resumidamente la argumentación expuesta en dicha sentencia por el Tribunal Supremo, es de poner de relieve que, tratándose como se trata de municipalización de servicios por gestión indirecta mediante concesión administrativa previo concurso aprobado por el Ayuntamiento y de tarifas que formaban parte de la concesión, que gozan del carácter de las tasas a percibir del público conforme a los números 1 y 3 del artículo 155 del Reglamento de Servicios de las Entidades locales de 27 de mayo de 1955 y que fueron autorizadas inicialmente por el Ministerio de la Gobernación en 8 de febrero de 1952, necesita la revisión, no sólo aprobación de la Corporación municipal, sino además de dicho Departamento ministerial por desprenderse así de la entrelazada exégesis de los artículos 179 de la Ley de Régimen local, texto refundido de 24 de junio de 1955, y 129, número $1, b$ ), del Reglamento de Servicios mencionado por un lado y de otro de los artículos 64 al 66 en relación con los 148 y 151 , números 1 y 3, de dicho ordenamiento reglamentario. (Sentencia de 4 de junio de 1974, Ar. 2.604).

\section{URBANISMO}

\section{Acción pública de la Ley del Suelo}

Si bien el Colegio de Arquitectos carece de interés concreto e individualizado en el asunto debatido, éste no es necesario en una acción como la que es objeto de contemplación en este caso, cuando también es insostenible que la acción pública de la Ley del Suelo no ampara las exigencias de cumplimiento de los Planes y Ordenanzas anteriores a dicha Ley y, por consiguiente, no aprobados con arreglo a la misma porque la infracción de las Normas Urbanísticas y de los Planes de Ordenación Urbana, aparte de las concretas lesiones que puede producir en los derechos patrimoniales $\mathrm{e}$ intereses legítimos de determinadas personas, asimismo lesiona el objeto del derecho al uso común por parte de todos los ciudadanos, y de ahí el que todos están facultados para defender el uso indebido de las Normas en vigor referentes a esta materia urbanística, y por ello, la acción pública protege contra toda infracción de ésta clase, cualquiera que sea su normativa aplicable y la fecha de su aprobación; y la Jurisprudencia, siguiendo esta tesis, ha reconocido la legitimación en los casos de ejercicio de la acción pública, por infracción de Ordenanzas municipales, aunque éstas estén aprobadas con anterioridad 
a la Ley del Suelo y por muy antiguas que fuesen, siempre que estuvieran vigentes, todo lo cual descarta el acogimiento de esta causa de inadmisibilidad. (Sentencia de 4 de mayo de 1974, Ar. 2.290).

\section{Expropiacion: falta de Planes parciales}

Considerando: Que, en cuanto al fondo de la cuestión planteada, las alegaciones del Ayuntamiento de Barcelona, que delimitan procesalmente la problemática de su apelación, se reducen a insistir en que el Plan Comarcal de Barcelona de 1953 es título justificativo de utilidad pública para la expropiación, mas tal argumentación no desvirtúa los razonamientos de la sentencia de la Audiencia, referidos a que tal Plan requiere el desarrollo posterior de los Planes parciales para su ejecución, en lo que se refiere a las obras urbanizadoras, y que con la sola base del mismo no queda determinado el objeto expropiado, por faltar la descripción material y detallada que exige el artículo 17, 2, de la Ley de Expropiación forzosa, por lo que a los efectos del artículo 10 de la misma, para legitimar la expropiación del inmueble, se requiere la aprobación de los Planes parciales, pues el artículo 4 de la Ley de 3 de diciembre de 1953 dispone que el «Plan Comarcal constituirá la base obligada para la redacción de los Planes parciales de Ordenación Urbana y de los proyectos de toda clase de obras»; precepto ratificado y desarrollado en la sección 4. ${ }^{a}$ del Reglamento de 22 de octubre de 1954, dictado para el desarrollo de dicha Ley, y que la determinación de los bienes expropiados requería la aprobación de los Planes parciales resulta no sólo de los artículos 41 y 42 del Reglamento, citados en la sentencia apelada, sino muy especialmente de la autorización concedida en el 45 para que al ser desarrollado en Planes parciales pueda ser modificado el Plan Comarcal, lo que evidencia que sólo en los Planes parciales quedan definitivamente especificados y concretamente determinados los bienes afectados, ello aparte de que con posterioridad a la aprobación del Plan Comarcal de 1953 se han producido modificaciones en la normativa legal y en la actuación planificadora en la Comarca de Barcelona, que hacen más convincente la apreciación de la sentencia de que por sus características genéricas, el Plan Comarcal, a efectos expropiatorios, requiere su desarrollo mediante los instrumentos adecuados. (Sentencia de 27 de mayo de 1974, Ar. 2.399).

\section{Planes generales: no pueden formularlos las Entidades}

\section{LOCALES MENORES}

Considerando: Que el fundamento de que las Entidades locales, cualquiera que sea su denominación, no puedan formular Planes de Urbanización radica forzosamente en que en si el artículo $90^{\circ}$ de la llamada Ley del Suelo enumera y exige, entre otros requisitos, la división del 
territorio en zonas y destino de cada una según las necesidades del programa urbano, la formulación de un Plan en la parte de un término municipal correspondiente a una Entidad local menor supondría, entre otras consecuencias, la interferencia en la soberanía municipal del Ayuntamiento a que perteneciese aquella Entidad local formuladora del Plan, con merma evidente de las decisiones que pudiera adoptar el Ayuntamiento afectado en la misma materia y que comprendiesen la parte de territorio en que estuviese situada aquella Entidad, porción del territorio municipal que quedaría sustraída a dichas decisiones.

ConsIDERANDo: Que esta razón es aplicable al régimen municipal peculiar de Navarra, porque el respeto que el artículo 209 de la Ley de Régimen local mantiene hacia él, ni le atribuye competencias que estén en desacuerdo con el régimen común, ni el Real Decreto de 4 de noviembre de 1925, dictado para las bases de aplicación del Estatuto municipal en aquella Provincia, contiene atribución alguna en materia urbanística a los Concejos navarros, siendo de aplicación, por tanto, la Ley de 12 de mayo de 1956, que tiene vigencia en todo el territorio nacional, puesto que no recoge excepción alguna en ese punto concreto. (Sentencia de 17 de junio de 1974, Ar. 2.681).

\section{ZONA MARITIMO-TERRESTRE}

\section{LINDERO CON EL MAR}

Como enseña la sentencia del Tribunal Supremo de 2 de enero de 1960, cuando en la descripción de una finca se hace referencia a la existencia de un linde con el mar, debe entenderse que tal lindero está constituido por la playa o por la zona marítimo-terrestre, sea pequeña o grande la extensión que deba darse a la mencionada zona, porque de entenderse lo contrario, cualquier imprecisa descripción de linderos podría perjudicar la conservación del uso público de las playas, infiriéndose de esta doctrina (que la finca del actor hay que entenderla colindante con la zona marítimo-terrestre o con el mar), lo que, unido a que por determinación de la Ley de Aguas de 1866 y Ley de Puertos de 1880, anteriores ambas a las primitivas escrituras de compra de los terrenos en discusión, la zona marítimo-terrestre o terreno que baña el mar en su flujo y reflujo, en donde son sensibles las mareas y las mayores olas, en los temporales, en donde no lo sean, son terrenos demaniales, de dominio nacional y uso público, por lo que gozan de todos los privilegios y presunciones que el Estado tiene establecido para la protección de los bienes demaniales; en consecuencia, la adquisición producida con posterioridad a la indicada normativa de bienes de esa clase no da titularidad alguna sobre la zona marítimo-terrestre. (Sentencia de 13 de mayo de 1974, Ar. 2.494).

Nemesio Rodríguez Moro 